\title{
Chemical and Biological Approaches for Adapting Proteostasis to Ameliorate Protein Misfolding and Aggregation Diseases-Progress and Prognosis
}

\author{
Susan L. Lindquist ${ }^{1}$ and Jeffery W. Kelly ${ }^{2,3}$ \\ ${ }^{1}$ Whitehead Institute for Biomedical Research, Department of Biology, Massachusetts Institute of Technology, \\ Howard Hughes Medical Institute, Cambridge, Massachusetts 02142 \\ ${ }^{2}$ Departments of Chemistry and Molecular and Experimental Medicine, The Scripps Research Institute, La Jolla, \\ California 92037 \\ ${ }^{3}$ The Skaggs Institute for Chemical Biology, The Scripps Research Institute, La Jolla, California 92037 \\ Correspondence: lindquist_admin@wi.mit.edu
}

\begin{abstract}
Maintaining the proteome to preserve the health of an organism in the face of developmental changes, environmental insults, infectious diseases, and rigors of aging is a formidable task. The challenge is magnified by the inheritance of mutations that render individual proteins subject to misfolding and/or aggregation. Maintenance of the proteome requires the orchestration of protein synthesis, folding, degradation, and trafficking by highly conserved/deeply integrated cellular networks. In humans, no less than 2000 genes are involved. Stress sensors detect the misfolding and aggregation of proteins in specific organelles and respond by activating stress-responsive signaling pathways. These culminate in transcriptional and posttranscriptional programs that up-regulate the homeostatic mechanisms unique to that organelle. Proteostasis is also strongly influenced by the general properties of protein folding that are intrinsic to every proteome. These include the kinetics and thermodynamics of the folding, misfolding, and aggregation of individual proteins. We examine a growing body of evidence establishing that when cellular proteostasis goes awry, it can be reestablished by deliberate chemical and biological interventions. We start with approaches that employ chemicals or biological agents to enhance the general capacity of the proteostasis network. We then introduce chemical approaches to prevent the misfolding or aggregation of specific proteins through direct binding interactions. We finish with evidence that synergy is achieved with the combination of mechanistically distinct approaches to reestablish organismal proteostasis.
\end{abstract}

Eukaryotic protein homeostasis, or proteostaEsis, is maintained by a diverse and complex network of integrated functions that sometimes synergize and sometimes compete to regulate the function of the proteome (Morimoto
1998; Balch et al. 2008; Morimoto and Cuervo 2009; Powers et al. 2009; Jarosz et al. 2010; Taipale et al. 2010). Compartment-specific stress-responsive signaling pathways regulate the function of this network, using sensors

Editors: Richard I. Morimoto, Dennis J. Selkoe, and Jeffery W. Kelly

Additional Perspectives on Protein Homeostasis available at www.cshperspectives.org

Copyright (C) 2011 Cold Spring Harbor Laboratory Press; all rights reserved; doi: 10.1101/cshperspect.a004507

Cite this article as Cold Spring Harb Perspect Biol 2011;3:a004507 
that can detect higher than normal levels of protein misfolding or aggregation (Didomenico et al. 1982; Morimoto 1998; Schroder and Kaufman 2005; Marciniak and Ron 2006; Ron and Walter 2007; Westerheide et al. 2009). In general, activation of stress-responsive signaling pathways in particular cellular compartments results in the synthesis and/or activation of regulators that orchestrate programs to enhance the proteostasis capacity of that compartment. Folding capacity almost always increases in concert with degradation capacity, highlighting the delicate balance between protein production, folding, and degradation (Balch et al. 2008; Morimoto and Cuervo 2009; Lee et al. 2010). Another key feature of stress-responsive signaling pathways is reduced transcription of normal cellular messages, reduced splicing of normal transcripts, and reduced translation of preexisting mRNAs (Yost et al. 1990; Shang et al. 2007; Ghosh et al. 2010). Importantly, these mechanisms sharply decrease the load on the proteostasis network and ensure the maximum possible response rates (Yost et al. 1990; Ron and Walter 2007; Shang et al. 2007; Ghosh et al. 2010). As proteostasis is restored through these highly orchestrated responses, regulatory pathways return to normal.

Concepts integral to systems biology must be invoked to comprehend the diverse functions and regulatory strategies harnessed by the proteostasis network (Vidal et al. 2011). Ribosome-associated chaperones (Maier et al. 2005; Merz et al. 2008) hand off proteins to multiple folding assistants including the HSP70-Hsp40nucleotide exchange factor folding pathway, the Hsp90-cochaperone folding pathway, or the TRiC chaperonin folding pathway in the cytosol (Ellis and Hartl 1999; Young et al. 2004; Tang et al. 2007; Voisine et al. 2010). How these work together as a system and in what order is poorly understood. The ubiquitin proteasome system is intimately linked to each of these chaperone systems by kinetic partitioning: futile attempts at folding eventually redirect terminally misfolded substrates to degradation (Lecker et al. 2006; Finley 2009). This both rids the cell of dangerous aggregation-prone species and reduces the load on the system.
Similar partitioning decisions link futile attempts by chaperone pathways to fold proteins to lysosomal degradation via autophagy (Kruse et al. 2006; Wong and Cuervo 2010; Arias and Cuervo 2011). There appear to be compensatory mechanisms that up-regulate autophagy when the proteasome is impaired and vice versa (Lamark and Johansen 2010; Zhu et al. 2010; Chen and Yin 2011).

Although we are far from a complete understanding of the system-level functions of the proteostasis network and its regulation, we now know enough about the control in the proteostasis network to begin to manipulate it to alleviate the deficiencies of proteostasis that lead to specific diseases (Westerheide et al. 2004, 2009; Westerheide and Morimoto 2005; Dai et al. 2007; Balch et al. 2008; Mu et al. 2008a,b; Cowen et al. 2009; Powers et al. 2009; Whitesell and Lindquist 2009; Tsaytler et al. 2011).

Importantly, the aggregation and misfolding of individual vulnerable proteins influence not only their own folding, but that of others sharing common proteostasis pathways (Powers et al. 2009). Even one mutated misfoldingprone protein can consume considerable capacity of the proteostasis network, and put other members of the proteome that require this capacity at risk of misfolding and aggregation (Gidalevitz et al. 2006). In turn, this leads to wider proteome misfolding or aggregation, if stress-responsive signaling cannot efficiently rebalance the system to match the network's capacity with demand (Balch et al. 2008). For reasons not well appreciated, organismal aging seems to attenuate stress-responsive signaling, and this hampers efforts by cells of aged organisms to restore proteostasis (Morley et al. 2002; Cohen et al. 2006, 2009, 2010; Ben-Zvi et al. 2009). Thus, enhancing stress-responsive signaling with small molecules is one way to counter the influence of a misfolding- or aggregation-prone protein in an organism and holds high promise for increasing healthy lifespans (Westerheide et al. 2004, 2009; Mu et al. 2008b).

Another approach is to make the energetics of a specific misfolding-prone proteins less problematic (Miroy et al. 1996; Sawkar et al. 
Approaches for Adapting Proteostasis

2002, 2006a; Cohen and Kelly 2003; Hammarstrom et al. 2003; Razavi et al. 2003; Johnson et al. 2005b, 2010; Tojo et al. 2006; Yu et al. 2007b; Choi et al. 2010a). Because the sequence of a protein specifies its folding, unfolding, misfolding, and aggregation kinetics (the latter being concentration dependent), this would at first glance seem to require sequence reprogramming-the largely unrealized goal of gene therapy. However, the energetics of an individual mutant protein prone to misfolding can be selectively tuned, if the folded state of that protein has a hydrophobic depression or cavity to which a small molecule can bind (Miroy et al. 1996; Sawkar et al. 2002, 2006a; Cohen and Kelly 2003; Hammarstrom et al. 2003; Razavi et al. 2003; Johnson et al. 2005b; Tojo et al. 2006; Yu et al. 2007b; Choi et al. 2010a). Small molecules that bind to the native state of mutant proteins lower their folding free energy and thus increase the folded population relative to the unfolded, misfolded, and aggregated states. This can also slow unfolding events that can lead to proteolysis or aggregation (Johnson et al. 2005b; Sekijima et al. 2006; Tojo et al. 2006). Indeed, targeting a particular protein prone to misfolding with a small molecule that binds the native state can restore the proteostasis not only of the energetically compromised protein, but of other proteins that use the same proteostasis network components (Gidalevitz et al. 2006). Unlike activators of stress-responsive signaling pathways, where one small molecule might be useful for multiple diseases $(\mathrm{Mu}$ et al. 2008b), native-state-binding small molecules are protein specific (Miroy et al. 1996; Fan et al. 1999; Fan 2001, 2003; Sawkar et al. 2002; Hammarstrom et al. 2003; Razavi et al. 2003; Sekijima et al. 2006; Tojo et al. 2006).

General strategies for rebalancing proteostasis are appealing because small shifts might be capable of ameliorating complex multifaceted problems and hold particular promise in combating aging-associated maladies. However, proteostasis networks are finely tuned and highly integrated, hence manipulating them does raise the specter of unintended side effects. Hence, both general and specific strategies are being explored and are exemplified below.

\section{General Introduction to Protein Folding}

Proteins are macromolecules made up of $\alpha$ amino acid residues connected together by amide bonds. They range in size from approximately 35 to more than one thousand amino acid residues and are often composed of more than one independently folding domain. The biosynthesis of proteins occurs on the ribosome, a complex riboprotein nanomachine that translates messenger RNA into a polypeptide chain. The linear synthesis of proteins performed by the ribosome in the amino- to carboxy-terminal direction allows individual domains to fold and/or be engaged by proteostasis network components (e.g., chaperones) before the entire protein is synthesized (Junker et al. 2009). The unique three-dimensional structures adopted by proteins enable their highly diverse functions, including acting as catalysts, intricate machines, and scaffolds of diverse cellular architectures. Many proteins assemble into larger quaternary structures either after or coincident with folding. Proteins also often contain at least one intrinsically disordered domain that enables the protein to participate in proteinprotein interactions with multiple protein partners, e.g., with proteins comprising a signaling cascade (Dyson and Wright 2005).

The chemical information encoded by the $\alpha$-amino acid sequence can be sufficient to enable the incredible process of protein folding to occur autonomously. Anfinsen won the Nobel Prize for demonstrating that small nonmembrane proteins can fold spontaneously at the low concentrations and temperatures used in experiments conducted in vitro (Anfinsen 1973). In the cell, protein folding is much more challenging than in a test tube owing to the very high protein concentration $(300 \mathrm{mg} /$ mL) (Ellis and Hartl 1999; Ellis and Minton 2006). This molecular crowding can lead to protein aggregation when partially folded states derived from the same protein or different proteins inappropriately interact. Thus, protein folding in the cell generally requires the assistance of the proteostasis network to be efficient (Young et al. 2004; Balch et al. 2008; Powers et al. 2009). In addition, proteostasis network 
enzymes catalyze or accelerate chemical processes like peptidyl-prolyl amide bond isomerization required for protein folding, which when uncatalyzed is simply too slow to support life.

On folding, multiple polypeptide chain reversals allow proteins to adopt compact structures stabilized by thousands of weak intramolecular electrostatic and hydrophobic interactions (Jager et al. 2001, 2008; Deechongkit et al. 2004). These interactions stabilize the folded ensemble - the conformationally related family of structures that comprise the functional or native state of nearly all proteins. The unfolded ensemble of conformations generated by the ribosome prior to folding has exposed hydrophobic side chains that are eventually desolvated and pack to make up the hydrophobic core of the protein. This process is aided by chaperones, which recognize the disproportionate number of contiguous exposed hydrophobic side chains found in unfolded but not folded ensembles (Ellis and Hartl 1999; Young et al. 2004; Ellis and Minton 2006). The unfolded ensemble is prone to aggregation if not bound by chaperones (Maier et al. 2005; Merz et al. 2008).
Most proteins show folding free energy diagrams that can be thought of as having a funnel shape (Fig. 1) (Onuchic and Wolynes 2004; Oliveberg and Wolynes 2005). The X and Y dimensions represent the conformational diversity in unordered or partially ordered ensembles of structures, whereas the Z-axis tracks energy. The folding funnel view of structure acquisition makes it clear that there are multiple pathways for arriving at the folded ensemble, and when the surface is rough, partially folded intermediates are populated (confirmed by experiments) that can be prone to aggregation and proteolysis (Onuchic and Wolynes 2004; Oliveberg and Wolynes 2005). Therefore, when proteostasis network capacity is sufficient, unfolded and partially folded ensembles are engaged by chaperones (Ellis and Hartl 1999; Young et al. 2004).

Folded proteins are generally only $-3 \mathrm{kCal} /$ $\mathrm{mol}$ (ratio of folded to unfolded is 160) to -7 $\mathrm{kCal} / \mathrm{mol}$ (ratio of folded to unfolded is $\mathrm{x} . \mathrm{y} \times$ $10^{\mathrm{z}}$ ) more stable than their unfolded ensembles. The small free energy of stabilization enjoyed by the folded conformational ensemble relative to the unfolded ensemble reflects the small difference between the large conformational entropy
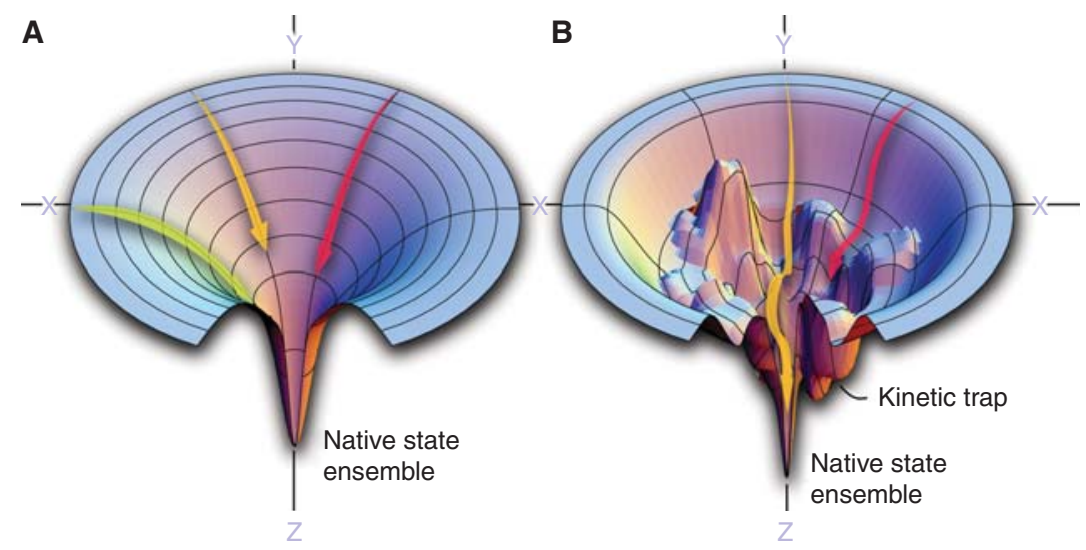

Figure 1. Energy landscape perspective on protein folding. In this view, individual positions in the X-Y-planes correspond to different protein conformations, which diminish in number as the polypeptide chain forms increasing numbers of native intrachain hydrophobic and electrostatic contacts, lowering the internal free energy as the protein approaches its native state conformational ensemble along the Z-axis. (A) A smooth folding funnel reveals the numerous pathways that a polypeptide chain can take to reach the folded conformational ensemble, reflected by the arrows moving down the folding free energy diagram. (B) A rougher folding free energy landscape also indicates that multiple parallel paths can be followed to reach the native state ensemble, however occasionally the polypeptide chain can get kinetically trapped in a folding intermediate (indicated by the red arrow). 
penalty associated with restricting the polypeptide chain to a few closely related conformations in the folded ensemble and the favorable solvent entropy associated with protein folding, the so-called hydrophobic effect (Kauzmann 1959; Kuntz and Kauzmann 1974). The hydrophobic effect drives protein folding by allowing thousands of water molecules to join the higher entropy liquid phase of water, on hydrophobic core formation associated with protein folding, rather than be required to form conformationally restricted ice-like structures to solvate hydrophobic side chains (Kuntz and Kauzmann 1974). In the unfolded ensemble, the backbone amides hydrogen bond with water, whereas in the folded conformation backbone-backbone amides form hydrogen bonds. Backbone-backbone hydrogen bonds are electrostatic interactions. Thus, backbone-backbone hydrogen bonds placed in a desolvated hydrophobic environment in the folded ensemble contribute more enthalpically to the stability of the folded ensemble than backbone hydrogen bonds to water, analogously to desolvated salt bridges (Deechongkit et al. 2004).

The same forces that drive intramolecular folding (including the hydrophobic effect mediated by hydrophobic side chain interactions and the liberation of ordered water molecules, backbone-backbone hydrogen bonding and salt bridge formation) also stabilize intermolecular complexes. Proteins that function as a complex are susceptible to aggregation when not bound to a partner, i.e., when freshly synthesized or when one component becomes limiting. Thus, the hydrophobic surfaces of naked (chaperone-free) partially folded proteins that are missing their partner need to be bound to chaperones to prevent the aggregation of proteins that make up a complex.

Proteins also have the ability to toggle between structurally related states in the folded ensemble of conformers. This allows one protein, e.g., an enzyme, to perform complex functions like substrate binding, stabilization of a transition state and product ejection. Switching between states in the folded ensemble, some of which have exposed hydrophobic side chains, also puts proteins, especially those at high concentrations, at risk for aggregation and proteolysis (Fig. 2). Thus, there are specialized chaperones like the Hsp90s that bind to proteins (like the unliganded nuclear hormone receptors) with exposed hydrophobic side chains (Li et al. 2011; Richter and Buchner 2011).

Folding is not over once it happens once: the folded ensemble is in dynamic equilibrium with the unfolded state throughout the life of the protein. This dynamic conformational behavior is important for protein function, as some proteins have to be unfolded postfolding to get them into cellular compartments (like the mitochiondria). All proteins have to be in an extended conformation to be degraded by proteases, such as the proteasome or lysosomal proteases, which recycle proteins into amino acids to be reused by the cellular machinery, including the ribosome, to remake proteins.

The ribosome is imperfect, thus mistakes in translation lead to proteins having the wrong amino acid sequence (Drummond and Wilke 2008; Powers and Balch 2008). Some of these proteins can be very challenging if not impossible to fold, further consuming proteostasis network capacity (Drummond and Wilke 2008; Powers and Balch 2008). Moreover, many of us inherit many proteins harboring missense mutations, some of which are folding deficient and capable of manifesting in misfolding or aggregation-associated diseases (Sawkar et al. 2006a). A common genetic alteration in humans and other organisms is gene duplication and triplication, which is known to confer increased risk for aggregation-associated diseases as a consequence of taxing the proteostasis network.

Even for small proteins, there is a constant kinetic competition between unimolecular protein folding leading to function, unimolecular misfolding leading to loss-of-function and concentration-dependent aggregation ( $\mathrm{Mu}$ et al. $2008 \mathrm{~b}$ ). A main function of the proteostasis network is to maximize the efficiency of folding and function and to miminimize misfolding and aggregation that compromises function, or worse leads to loss- or gain-of-toxic-function misfolding diseases (Fig. 3) (Cohen and Kelly 2003; Balch et al. 2008; Powers et al. 2009). 


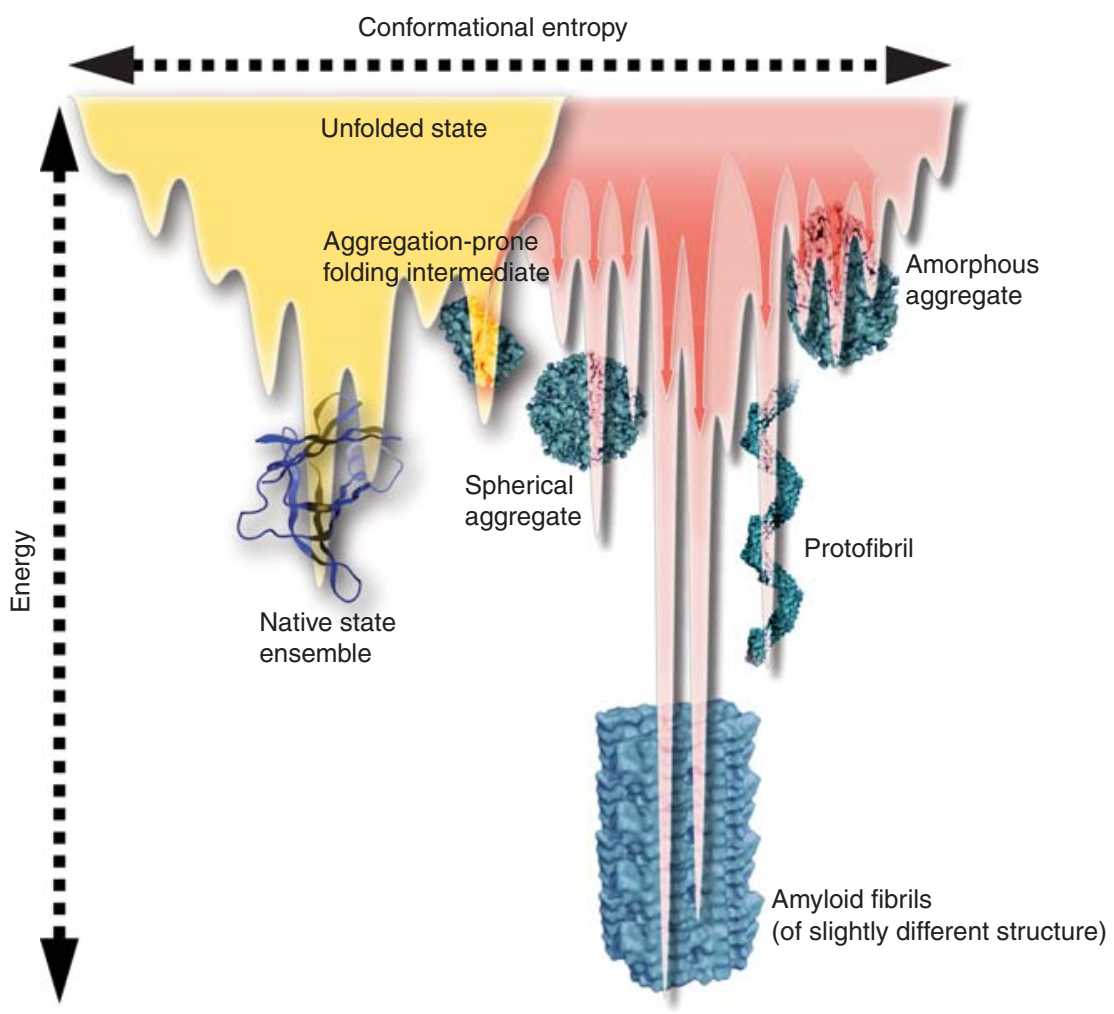

Figure 2. A combined energy landscape for protein folding vs. aggregation. A slice through a rough folding free energy landscape diagram (in yellow) of the type depicted in Figure 1, demonstrating that the population of a folding intermediate at high enough concentration can lead to the formation of aggregate structures (red arrow) having distinct structures and energies, some of which are more stable than the native state. The depicted intermediate could also be populated from conformational excursions from the native state ensemble. The aggregation free energy landscape (in red) is much rougher than the folding free energy diagram. (Figure adapted from Jahn and Radford [2008] and reprinted, with permission, from Elsevier (C) 2008.)

Even when proteostasis network function is optimal, misfolding and aggregation still occurs and it is important that the proteostasis network degrade these states by directing these structures to the proteasome and/or the lysosome (autophagy) for degradation if proteostasis network mediated refolding is not possible (Finley 2009; Arias and Cuervo 2011). Both misfolding and aggregation are favored by higher growth temperatures, such as at $37^{\circ} \mathrm{C}$, in which the human proteome has to fold and function. Because protein folding and unfolding occur throughout the life of a protein, and because of the high kinetic energy associated with collisions between proteins in the crowded cell, aggregation is particularly problematic.
The dynamic nature of protein folding, the modest intrinsic driving forces stabilizing the folded ensemble, and the ability to access nonnative and aggregated states when mistakes are made or when mutated proteins are inherited explain why the proteostasis network is required to assist and enable efficient protein folding in the cell. It follows that protein misfolding and aggregation are particularly problematic when proteostasis network capacity decreases, i.e., on aging (Morley et al. 2002; Cohen et al. 2006, 2009, 2010; Gidalevitz et al. 2006; BenZvi et al. 2009; Morimoto and Cuervo 2009). For these reasons and others, the proteostasis network capacity of individual cellular compartments is monitored by stress-responsive 


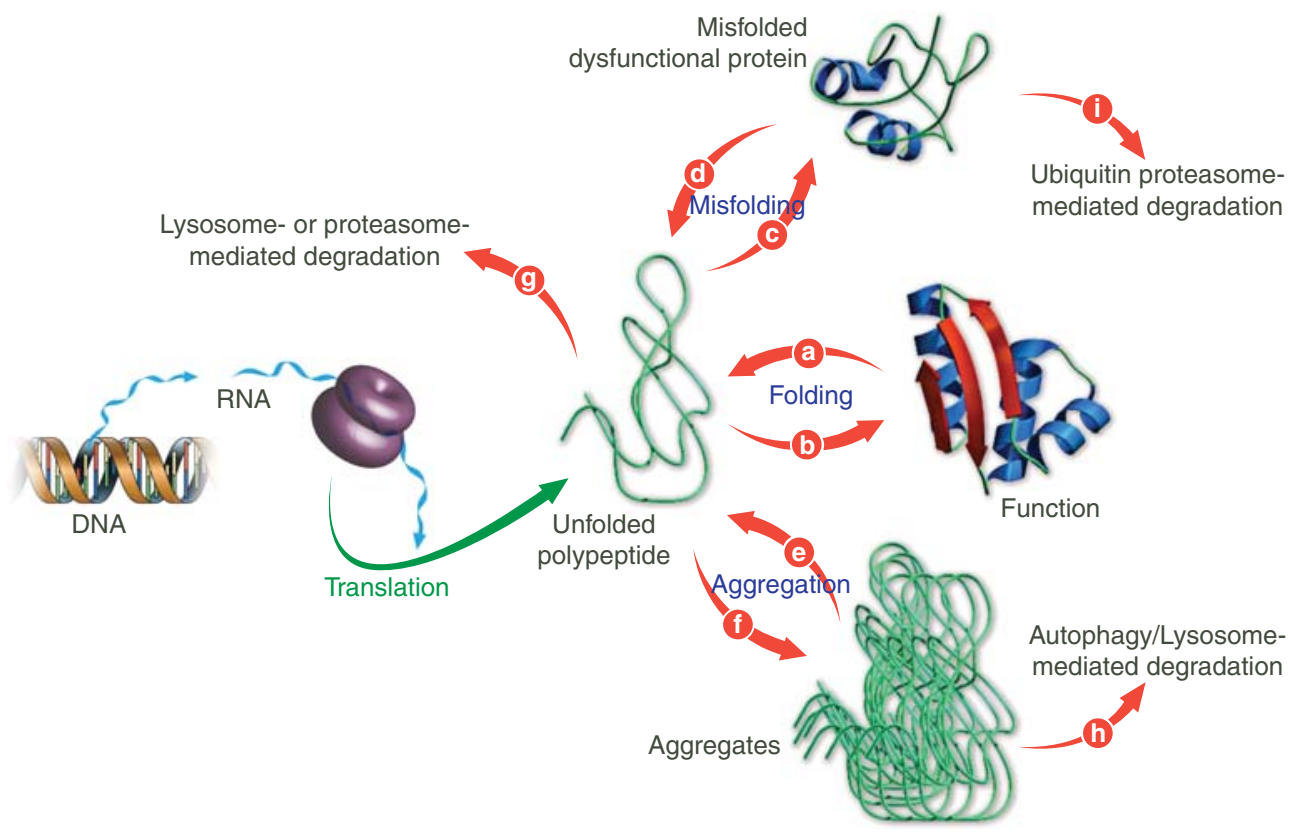

Figure 3. The kinetic competition between unimolecular folding, unimolecular misfolding and concentration dependent aggregation is strongly influenced by the proteostasis network. Maximizing unimolecular folding and function by minimizing misfolding and aggregation is a main role of the protein homeostasis network. The proteostasis network is a compilation of integrated and competitive biological pathways that influence the balance between folding, trafficking and degradation, activities depicted by arrows b,d,e,f,g,h, and i. Proteostasis network pathways include ribosome-mediated protein synthesis, chaperone and enzyme mediated folding, lysosome and proteasome-mediated protein degradation, and vesicular trafficking. (Figure adapted from Balch et al. [2008] and reprinted, with permission, from the American Association for the Advancement of Science.)

signaling pathways and other cellular pathways and adjusted in real time if insufficient (Didomenico et al. 1982; Morimoto 1998; Westerheide et al. 2004, 2009; Schroder and Kaufman 2005; Dai et al. 2007; Ron and Walter 2007; Balch et al. 2008; Prahlad et al. 2008; Whitesell and Lindquist 2009; Akerfelt et al. 2010; Jarosz et al. 2010).

Introduction to Protein Folding in the Cytosolic/Nuclear Compartment and the Heat Shock Response Which Matches Proteostasis Network Capacity There

The heat shock response stress-responsive signaling pathway is capable of sensing an abnormally high level of misfolded or aggregated proteins in the contiguous cytosolic/nuclear compartment. When sensed, this pathway triggers a transcriptional and posttranscriptional program that matches proteostasis network capacity with demand (Fig. 4). To maintain sufficient proteostasis network capacity for cytosolic and nuclear proteins, the heat shock response stress-responsive signaling pathway reduces the load on the proteostasis network by stopping nonessential protein synthesis and degrading mRNA, whereas at the same time increasing the concentration of proteostasis network components through transcription and translation. Excess chaperone capacity, especially Hsp90 binding to the transcription factor heat shock factor-1 (HSF1), in combination with other regulatory mechanisms (acetylation and dephosphorylation of HSF-1) turn off heat shock response signaling when 


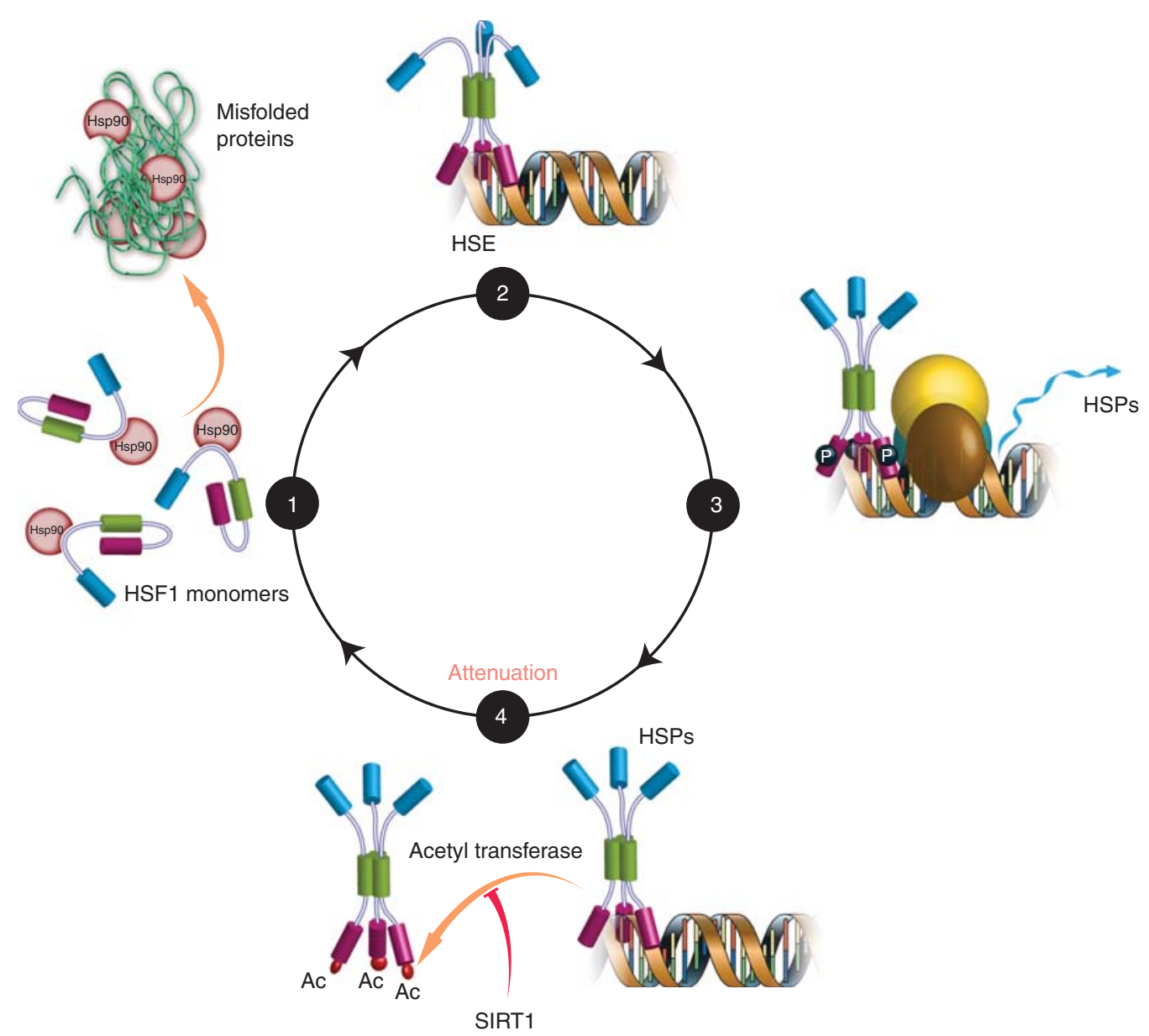

Figure 4. The mammalian heat shock response stress responsive signaling pathway matches proteostasis network capacity with demand in the cytosol. The heat shock response is turned on by Hsp90 being recruited away from the transcription factor HSF1 to deal with aggregation and/or misfolding. This allows the HSF1 transcription factor to trimerize and be phosphorylated, which initiates transcription of genes harboring the heat shock response element (HSE). Phosphatases and acetyl transferase enzymes negatively regulate the heat shock response, as does Hsp90 expression that rebinds HSF1.

proteostasis network capacity exceeds demand (Fig. 4) (Didomenico et al. 1982; Rieger et al. 2005; Westerheide and Morimoto 2005; Balch et al. 2008; Westerheide et al. 2009; Akerfelt et al. 2010).

Although an understanding of the proteostasis network function of the cytosol from a systems perspective is lacking, we do have a largely complete parts list and a partial understanding of how some pathways within the cytosolic proteostasis network function (Hartl and Hayer-Hartl 2009). The ribosome is a major and integral component of the cytosolic/ nuclear proteostasis network that has to be made from numerous RNA and protein components (Powers and Balch 2008; Mulder et al. 2010). An early and critical event in heat shock response signaling is the translation attenuation of nonproteostasis network components by the ribosome (Didomenico et al. 1982; Akerfelt et al. 2010). Ribosome-associated chaperones like $\alpha$ - and $\beta$-NAC function to minimize the aggregation of several copies of the same protein undergoing translation from a 
polysome (multiple ribosomes translating a single mRNA) (Maier et al. 2005; Merz et al. 2008; Albanese et al. 2010). It has become clear that the structure of the polysome is such that the ribosome exit sites are positioned as far apart as possible in $3 \mathrm{D}$ space to minimize aggregation (Brandt et al. 2010). The $\alpha$ - and $\beta$-NAC holdase chaperones (Maier et al. 2005; Merz et al. 2008; Albanese et al. 2010) likely hand off largely unfolded proteins to a variety of chaperone and chaperonin pathways. These include the workhorse Hsp70-Hsp40-nucleotide exchange factor folding pathways (Kampinga and Craig 2010) and the TRiC CCT chaperonin pathways (Tang et al. 2008; Zhang et al. 2010; Douglas et al. 2011), respectively. It remains unclear to what extent the Hsp90-cochaperone folding pathway primarily folds proteins_-it is clear this pathway is critical for enabling largely folded proteins to bind ligands and perform complex functions (Li et al. 2011; Richter and Buchner 2011). There are also non ATP-hydrolyzing enzymes, e.g., peptidyl prolyl isomerases, that also work in concert with the ATP hydrolyzing chaperone/chaperonin pathways to enable protein folding (Fischer and Schmid 1999; Edlich and Fischer 2006). The small heat shock proteins and the NACs are examples of chaperones that partition between high- and lowaffinity states without using ATPase activity (Haslbeck et al. 2005). Although it is clear that folding and degradation by the ubiquitin proteasome system and the lysosome, likely mediated by the process of autophagy, is linked to frustrated chaperone/chaperonin-mediated folding (DeMartino and Gillette 2007; Finley 2009; Kon and Cuervo 2010; Smith et al. 2011), it remains to be worked out exactly how the degradation decisions are made. The degradation of aggregated and chronically misfolded proteins is critical to prevent depletion of that protein from the soluble pool and the sequestration of other functional proteins by aggregates to prevent a gain-of-toxic-function phenotype (Olzscha et al. 2011), the origins of which are only partially understood.

It is important to realize that the vast majority of proteins that function in the mitochondria are encoded by the nuclear genome, and thus are handled by the nuclear/cytosolic proteostasis network before they are imported into the mitochondria by the TOM/TIM mitochondrial import machinery. The mitochondrial proteome, e.g., that of the electron transport chain, is particularly susceptible to damage by reactive oxygen species and therefore the stress-responsive signaling pathway unique to the mitochondria and transmitted to the cytosolic/nuclear compartment has to be vigilant for this type of misfolding and aggregation inducing modifications. Unlike the oxidizing environment of the secretory pathway (discussed below), that facilitates disulfide bond formation, the cytosol is a reducing environment; thus few cytosolic proteins have stabilizing disulfide bonds. The lack of stabilizing disulfide bonds allows more frequent excursions to unfolded and partially folded states, putting the cytosolic proteome at high risk of aggregation. This is especially true considering the very high protein concentrations found in the cytosolic compartment. Moreover, as mentioned below, this compartment makes riboproteins, which are particularly challenging to assemble owing to the large number of components and extremely complex topology. The central importance of ribosomes in physiology and the critical function of the conformationally fragile and aggregation-prone tumor suppressors in the cytosol and in the nucleus are but two of many reasons why the cytosolic/ nuclear proteostasis network function is so critical to organismal fitness.

Heat shock response signaling activators are appealing for rebalancing proteostasis in the cytosolic and nuclear compartments because small shifts might be capable of ameliorating complex multifaceted problems and hold particularly promise in combating aging-associated maladies (Morley and Morimoto 2004; Westerheide and Morimoto 2005; Balch et al. 2008). However, it has been shown that heat shock response signaling is critical for the propagation of some cancers and for the emergence of drug resistant viruses (Whitesell and Lindquist 2005, 2009; Dai et al. 2007; Geller et al. 2007). Hence, activating the heat shock response could result in unintended side effects 
and therefore vigilance for mechanism-based toxicity from heat shock response activators in human clinical trials will be important.

\section{ADAPTATION OF THE PROTEOSTASIS NETWORK TO AMELIORATE MISFOLDING AND AGGREGATION DISEASES}

Activating the Heat Shock Response and FOXO Signaling to Ameliorate Degeneration of Postmitotic Tissue Associated with Protein Aggregation

Aging is the single most important risk factor for the onset of aggregation-associated degenerative diseases, such as Alzheimer's disease, Huntington's disease, and Parkinson's disease (Morley et al. 2002; Chaney et al. 2003; Morley and Morimoto 2004; Cohen et al. 2006, 2009, 2010; Weissman et al. 2007; Tatsuta and Langer 2008; Ben-Zvi et al. 2009; Morimoto and Cuervo 2009; Schue 2009; Smaili et al. 2009; Douglas and Dillin 2010). Aggregate accumulation largely targets the degeneration of tissues that cannot regenerate (postmitotic tissues). The maintenance of protein homeostasis is challenged on aging because of the decreasing responsiveness of stress-responsive signaling pathways, increasing oxidative protein damage, and other factors that are only beginning to be understood from a mechanistic perspective, such as transcriptional attenuation of stress-responsive signaling (Zhang et al. 2004; Bieschke et al. 2006; Bosco et al. 2006; Ben-Zvi et al. 2009). There is a possibility that by pharmacologically restoring the proteostasis capacity of the cytosol to young adult levels in the aged, we could reverse numerous agedependent neurological diseases and perhaps other diseases such as cardiomyopathies and muscle wasting diseases (Balch et al. 2008; Powers et al. 2009). In support of this hypothesis, below we summarize evidence that enhancing cytosolic proteostasis capacity alleviated proteotoxicity in organismal models of degenerative diseases linked to protein aggregation.

A reduction in insulin growth factor-1 receptor signaling allows the Daf-16 and HSF-1 transcription factors to enter the nucleus, extending the lifespan of Caenorhabditis elegans nearly twofold and that of mice by $30 \%$ (Arantes-Oliveira et al. 2002; Dillin et al. 2002; Morley and Morimoto 2004; Kenyon 2005). In addition to the extension of lifespan, reducing insulin growth factor-1 receptor signaling (Fig. 5) also offers dramatic protection from proteotoxicity in worm and mouse models of Alzheimer's and Huntington's diseases (Morley et al. 2002; Cohen et al. 2006, 2009, 2010).

High levels of insulin growth factor-1 receptor signaling negatively regulates HSF1, the transcription factor mediating the heat shock response responsible for maintaining cytosolic proteostasis introduced above (Morley and Morimoto 2004). Substantial insulin growth factor-1 receptor signaling also negatively regulates Daf-16 (FOXO) that transcriptionally regulates metabolic enzymes/cytosolic proteostasis network components and influences degradation pathways (Fig. 5) (Arantes-Oliveira et al. 2002; Dillin et al. 2002). Applying RNAi to the sole insulin growth factor receptor delays the aging-associated gain-of-proteotoxicity phenotype in C. elegans models of Huntington's and Alzheimer's diseases (Morley et al. 2002; Hsu et al. 2003; Morley and Morimoto 2004; Kenyon 2005; Cohen et al. 2006).

Huntington's disease is caused by expansion of a contiguous polyglutamine tract in exon 1 of the huntingtin protein (Gusella and MacDonald 2009). When the polyglutamine expansion exceeds a threshold length of about 40 residues, aggregation and neurotoxicity can occur, with an age of onset that roughly inversely correlates with the length of the polyglutamine repeat in humans and organismal models. It has been surmised that the variability in the age of onset in Huntington's disease is a direct consequence of cytosolic proteostasis network capacity (Morley et al. 2002; Gidalevitz et al. 2006; Voisine et al. 2010).

Alzheimer's disease also appears to be linked to a more global loss of proteostatic control, as reflected by the intra- and extracellular aggregation of $A \beta$ and the intracytoplasmic aggregation of hyperphosphorylated tau protein, with an age of onset typically after the sixth decade in humans (Selkoe 2004, 2008; Tanzi and Bertram 


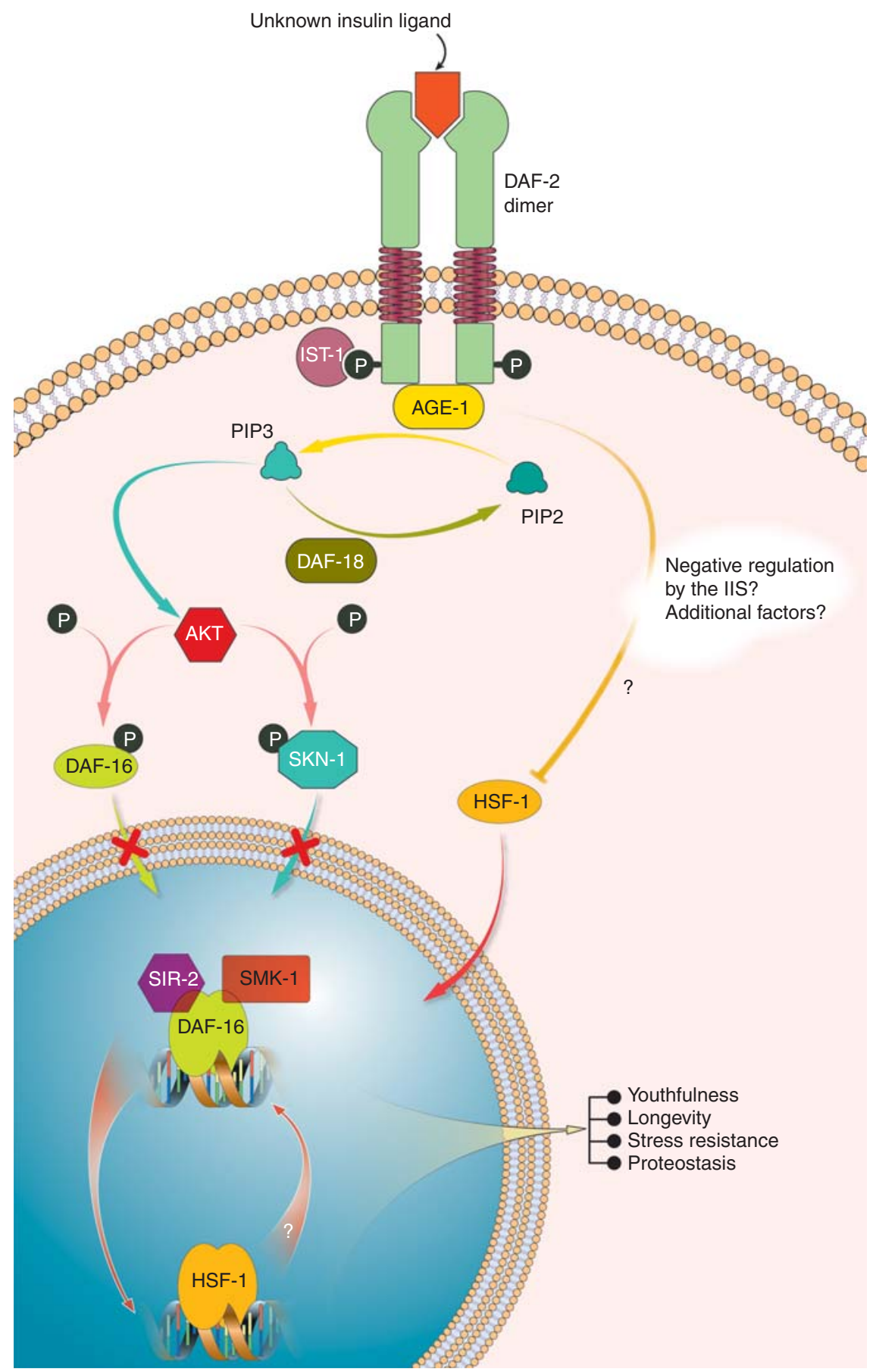

Figure 5. Reduced insulin growth factor signal enhances cytosolic proteostasis network capacity by activating the heat shock response and foxo signaling. The binding of a currently undefined ligand to the insulin/insulin-like growth factor receptor DAF-2 in C. elegans triggers insulin/insulin-like growth factor (IGF-1) signaling that negatively regulates the HSF-1 transcription factor and the FOXO transcription factor, DAF-16. Thus, reduced IGFR signaling permits increased HSF-1 and DAF-16 signaling which enhances proteostasis network capacity while also strongly influencing metabolism. 
2005). As mentioned above, the transcription factor HSF1 is activated by reduced insulin growth factor-1 receptor signaling, which in turn results in a heat shock response, enhancing the proteostasis network capacity of the cytosol (Fig. 5) (Morley and Morimoto 2004; Westerheide et al. 2009). It is notable that activating the heat shock response, along with the FOXO pathway, protects the organisms from the proteotoxicity linked to aggregation in Alzheimer's and Huntington's disease in animal models through mechanisms that are being sought, but appear to involve alterations in proteostasis (Morley et al. 2002; Hsu et al. 2003; Morley and Morimoto 2004; Kenyon 2005; Cohen et al. 2006, 2009). What is interesting is that there are actually more $A \beta$ amyloid fibrils in the insulin growth factor-1 receptor RNAi treated worms than in the untreated worms, which show stark proteotoxicity, supporting other evidence in both Alzheimer's and Huntington's diseases that amyloid fibrils per se may not be central to pathology (Cohen et al. 2006). Instead, the process of amyloidogenesis appears to be the genesis of the degeneration of postmitotic tissue (Cohen et al. 2006). Currently, there is considerable focus on the aggregates that precede fibrils, so-called oligomers, as the proteotoxic species in these degenerative diseases, and it is important to probe the influence of these pathways on oligomer distribution (Lambert et al. 1998; Lashuel et al. 2002; Walsh et al. 2002; Selkoe 2008). RNAi depletion of HSF1, preventing the heat shock response, or introduction of another misfolding-prone protein to consume proteostatic network capacity both exacerbate polyglutamine or $A \beta$ aggregation-associated proteotoxicity (Cohen et al. 2006; Gidalevitz et al. 2006). Conversely, overexpressing certain chaperones, including Hsp70, Hsp40, and CCT, as another means to reestablish proteostasis suppresses aggregation-associated proteotoxicity in numerous neurodegenerative disease models (Namba et al. 1991; Auluck et al. 2002; Behrends et al. 2006; Kitamura et al. 2006; Tam et al. 2006). We prefer activating the heat shock response stress-responsive signaling pathway to upregulate profolding, aggregation avoidance and prodegradation functions in concert to avoid the unanticipatable, potentially undesirable consequences of perturbing the proteostasis network by manipulating the concentration of an individual chaperone or the like.

Directing RNAi against downstream components of the insulin growth factor-1 receptor signaling pathway, e.g., against age-1-a phosphoinositide-3 kinase, also mediates slowing of the aging process and an increase in cytosolic proteostasis network capacity in $\mathrm{Q}_{82}$-expressing worms, conferring protection from aggregation-associated proteotoxicity (Morley et al. 2002). This result further shows that the adaptable biology of the proteostasis network, also apparently important for longevity, is critical for achieving a life free of degenerative diseases.

A reduction in insulin growth factor-1 receptor signaling as a means to ameliorate proteotoxicity and neuronal loss was also recently shown in a mouse model of Alzheimer's disease (Cohen et al. 2009). These data show that increased HSF-1 and FOXO signaling to enhance the cytosolic proteostasis network capacity and protect against neurodegeneration can be extended to mammals. The mouse model features two Alzheimer's disease-linked mutated transgenes, both driven by the mouse prion protein promoter. These include a humanized version of mouse amyloid precursor protein harboring the two Swedish mutations preceding the $A \beta$ sequence and a mutated human presenilin-1 $\Delta$ E9 $\gamma$-secretase component (Jankowsky et al. 2001). Reduced insulin growth factor-1 signaling dramatically protected this murine model from Alzheimer's disease-like symptoms, including reduced neuroinflammation, neuronal loss, and behavioral impairments (Cohen et al. 2009). As was also the case in the worm model of Alzheimer's disease, protection from proteotoxicity correlated with increased levels of $\mathrm{A} \beta$ aggregates and increased plaque density, as revealed by the $A \beta$ kinetic aggregation assay (Cohen et al. 2009; Du et al. 2011). These findings show that a reduced insulin growth factor- 1 signaling-regulated mechanism that protects from $\mathrm{A} \beta$ proteotoxicity is conserved from worms to mammals. Thus, modulation of this signaling pathway and/or the 
heat shock response may be a promising strategy for the development of Alzheimer's disease drugs for aged men and women (Cohen et al. $2006,2009,2010)$. This is especially true since it was recently shown that a reduction in insulin growth factor-1 signaling also protected against neurodegeneration after the neurodegenerative phenotypes appear (Cohen et al. 2010).

\section{Activating Protein Degradation by the Proteasome to Reestablish Cytosolic Proteostasis}

A plethora of evidence suggests that the accumulation of aggregated proteins in the cytosol appears to cause degenerative diseases, including Huntington's disease and Parkinson's disease, among many others (Selkoe 2004; Gusella and MacDonald 2009). Thus, a recent paper demonstrating activation of the proteasome through USP14 small molecule inhibition represents a promising strategy to clear aggregated proteins and potentially ameliorate these maladies (Lee et al. 2010). Cytosolically localized proteasomes are the primary mediators of ubiquitin-conjugated protein degradation - an activity regulated through poorly understood mechanisms. The proteasome-associated deubiquitinating enzyme USP14 inhibits the degradation of ubiquitin-protein conjugates both in vitro and in cells by deubiquitinating the proteasome-bound ubiquitinated client proteins. The active-site-directed thiol protease inhibitor 1[1-(4-fluorophenyl)-2,5-dimethylpyrrol-3-yl]2-pyrrolidin-1-ylethanone appears to only bind to activated USP14 docked on the proteasome, inhibiting the trimming of ubiquitin chains by USP14 (Lee et al. 2010). This small molecule inhibitor of USP 14 can enhance tau degradation in cells, highly relevant because the aggregation of tau is established to play a causative role in Alzheimer's disease. Because ubiquitin chain trimming of proteasome clients by USP 14 seems to be a general, but not universal, mechanism for regulating protein turnover rates, future studies will be required to see how applicable this approach is to other disease-associated proteins that show a propensity for intracellular aggregation and proteotoxicity (Lee et al. 2010). A modest reduction in cytosolic concentration of an aggregation-prone protein can dramatically inhibit aggregation owing to the high order concentration dependence of the kinetics of the aggregation reactions (Hurshman et al. 2004).

\section{Altering Chaperone-Cochaperone Interactions to Enhance Degradation at the Expense of Folding in the Cytosol}

Chaperone-cochaperone systems can facilitate either folding or degradation and, as mentioned in the introductory section of this article, there is usually a balance struck between these two functions. To better understand how chaperones make this important triage decision, the Gestwicki laboratory has discovered small molecules that control the ATPase activity of Hsp70. Importantly, they designed their screens to reveal both inhibitors and activators to gain insight into how this enzymatic function regulates the fate (e.g., folding vs. degradation) of Hsp70-bound substrates (Chang et al. 2008; Miyata et al. 2010). Using this approach, they found that inhibitors of ATPase activity lead to proteasome-dependent degradation of microtubule-binding protein tau in a cell-based model (Fig. 6), while activators of Hsp70 preserved normal cytoplasmic tau levels (Jinwal et al. 2009). Interestingly, Hsp70 ATPase inhibition did not lead to global protein degradation but, rather, the pharmacological effect seemed somewhat selective for tau (and a handful of other Hsp70 clients) and they appeared to avoid activation of a stress response (Jinwal et al. 2009; Koren et al. 2010). The mechanisms if this selectivity are still under investigation; however, one aspect that is likely important is that these compounds do not impact ATP turnover by competitive mechanisms. Rather, they bind at protein-protein interfaces to more subtly tune the chaperone response by controlling cochaperone recruitment. For example, in collaboration with the Brodsky and Zuiderweg laboratories, they identified compound 115-7c and defined its ability to mimic Hsp40's ability to stimulate Hsp70's ATPase activity. This compound partially compensated for lack of Hsp40 function in yeast, further suggesting its role as 
S.L. Lindquist and J.W. Kelly

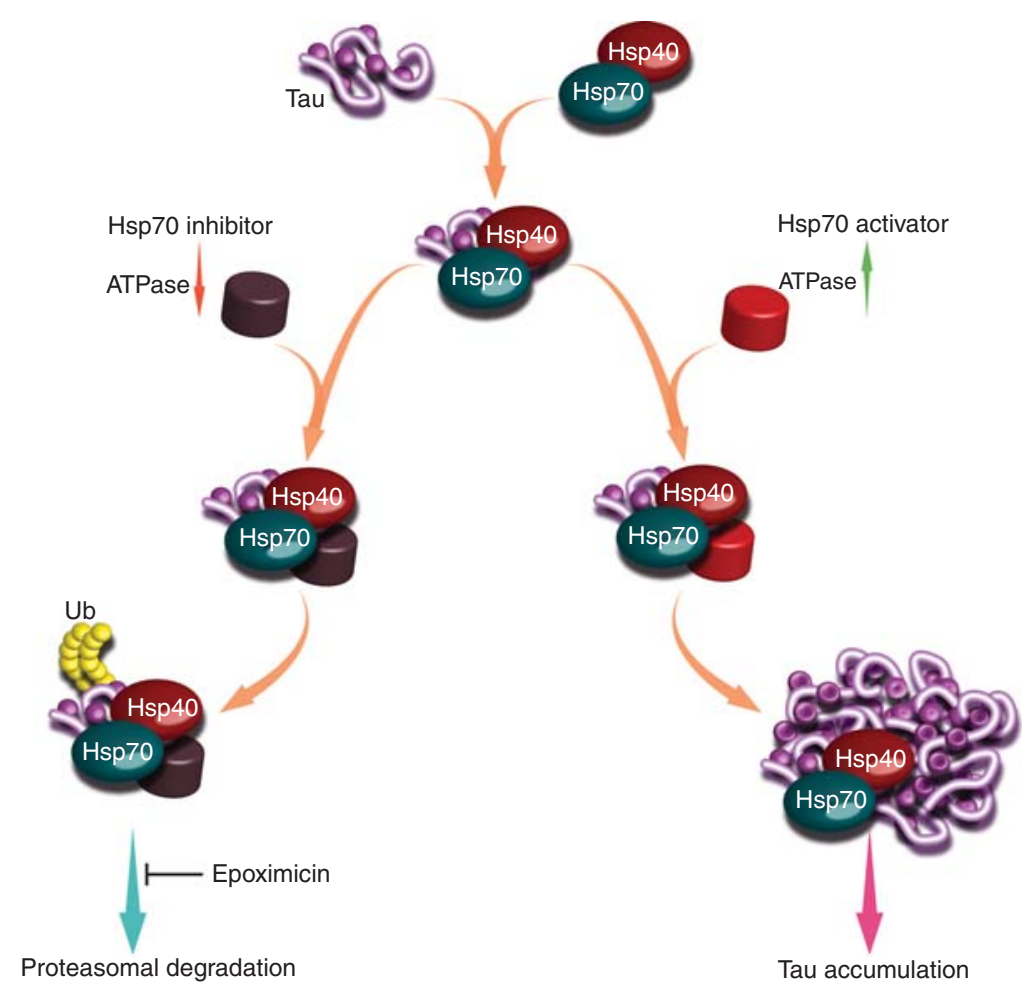

Figure 6. Tau degradation vs. accumulation by tuning the Hsp70-Hsp40-nucleotide exchange factor pathway. Triage decisions involving the Hsp70-Hsp40 complex can be "tuned" using small molecules. By stimulating the Hsp70-Hsp40 interaction and Hsp70 ATPase activity, the stability of an Hsp70 substrate, tau, was increased. Alternatively, blocking the Hsp70-Hsp40 interaction led to ubiquitination and degradation of tau. Figure kindly provided by Jason Gestwicki.

an activator at an important protein-protein contact (Wisen et al. 2010). Interestingly, NMR and mutagenesis studies reveal that the binding site for this small molecule is a site on Hsp70 that is adjacent to where the J-domain of Hsp40 binds. Accordingly, Hsp40 and compound $115-7 \mathrm{c}$ act in concert to stimulate Hsp70 ATPase activity. Based on these findings, the Gestwicki group has recently conducted more focused screens to identify additional molecules that regulate the Hsp70-Hsp40 interaction. In these screens, a mixture of purified Hsp70 and Hsp40 was used as the target and, using this approach, they found that the identified inhibitors are enriched for those that target the Hsp70-Hsp40 interaction without affecting other cochaperone contacts (Chang et al. 2011). Based on these findings, the authors suggest that reconstituted chaperone-cochaperone complexes have the potential to be powerful drug targets and, by specifically controlling the way that cochaperones bind Hsp70s, features of proteostasis might be very selectively tuned (Chang et al. 2010; Evans et al. 2010).

\section{Hsp-90 Inhibitors to Induce the Heat Shock Response}

Because Hsp90 is established to negatively regulate the HSF1 transcription factor, preventing induction of the heat shock response, many have surmised that the Hsp90 inhibitors, currently in late stage clinical trials as anticancer agents, could be useful for heat shock response induction (Bagatell and Whitesell 2004; Whitesell and Lindquist 2005; McDonald et al. 2006; Voellmy and Boellmann 2007; Cowen et al. 2009; Taipale et al. 2010; Trepel et al. 2010; 
Richter and Buchner 2011). However, since Hsp90 performs many useful functions, inhibiting it will likely cause aggregation and misfolding of many proteins (Richter and Buchner 2011) and therefore may not be the best way to induce the heat shock response. Nevertheless, inhibition of Hsp90 might be useful if this stress is applied infrequently to increase the capacity of the organism to deal with chronic protein aggregation or misfolding.

\section{The Proteostasis Challenges of the Endoplasmic Reticulum Secretory Compartment}

Roughly one-third of the human proteome passes through, or resides in, the endoplasmic reticulum (ER) secretory compartment (Fewell et al. 2001; Schroder and Kaufman 2005; Ron and Walter 2007). Proteins traffic through the ER to get to the Golgi, the lysosome, and the extracellular space-via highly dynamic networks of membrane-bounded vesicles. These bud from one subcompartment and fuse with the next in a tightly regulated fashion. The proteome of this multifaceted compartment faces all of the problems that proteins in the cytosolic/nuclear compartment encounter, including extreme crowding, the high kinetic energy of protein collisions that can facilitate aggregation, and the low folded state free energy of the secreted proteome that makes it susceptible to misfolding and degradation as well as aggregation, potentially leading to loss- and gainof-toxic-function diseases, respectively (Cohen and Kelly 2003; Mu et al. 2008b). But in other respects, the ER represents a very different environment in which to create a proteome. Only recently have we realized that this difference likely originates from the early derivation of eukaryotic cells from the combination of archaeal and eubacterial lineages (Koonin 2010). Hence, most of the secreted proteome that passes through the ER is cotranslationally modified by branched glycans attached to the side chain of Asn. So-called N-glycosylation is key to both folding efficiency and function for both intrinsic reasons (the conserved $\mathrm{N}$-glycan makes native state and/or transition state stabilizing interactions with the protein (Culyba et al. 2011)) and extrinsic reasons (N-glycosylated glycoproteins use glycan and protein binding chaperones that are only found in the ER) (Yoshida 2003; Williams 2006). Moreover, the environment of the ER is highly oxidizing. Cysteine residues are almost always enzymatically oxidized into disulfide bridges in the ER and each must eventually find and pair with its correct partner-a process facilitated by enzymes that catalyze disulfide interchange reactions.

These are problems of staggering proportions, and the proteostasis network of the $\mathrm{ER}$, and secretory pathway more generally, is commensurately more complex. The ER versions of the Hsp70 and 90 chaperone families play important roles in folding, but proteins unique to the ER are equally critical: the lectin chaperones calnexin and calreticulin that help $\mathrm{N}$-linked glycoproteins to fold (Ellgaard et al. 1999; Williams 2006), UDP-glucose-glucosyl transferase that allow $\mathrm{N}$-linked glycoproteins to use the calnexin/calreticulin folding/degradation pathways more than once, and the glucosidases that target chronically misfolded proteins to ER-associated degradation (Williams 2006). There are also numerous protein processing proteases, and protein disulphide oxidases, to name but a few (Schroder and Kaufman 2005; Ron and Walter 2007).

All proteins residing in and passing through the secretory pathway more generally, are encoded by nuclear genes. These proteins are cotranslationally inserted into the endoplasmic reticulum (ER) through the translocon, a complicated machine that enables membrane proteins to be inserted into the membrane with the proper topology and ER soluble proteins to pass through the translocon in a largely unfolded conformation that is read out by the oligosaccharyl transferase enzyme that sometimes attaches an N-glycan en bloc when it detects an Asn-Xxx-Ser/Thr "sequon" (Shan and Walter 2005; Johnson 2009; Larkin and Imperiali 2011). There is no system for degrading misfolded proteins within the confines of the ER that we know of. Rather, proteins must either be exported back into the cytoplasm for degradation by the proteasome (Werner 
et al. 1996; Brodsky and McCracken 1997; McCracken et al. 1998; McCracken and Brodsky 2003) or delivered by vesicle trafficking to the lysosome by one of several possible mechanisms (Kruse et al. 2006; Kon and Cuervo 2010). Both pathways are complex and tightly regulated.

Stress-Responsive Signaling to Maintain Proteostasis in the Endoplasmic Reticulum and Beyond

For many years, it was mysterious how proteostasis problems within the membrane-bounded sanctuary of the ER could be perceived by, and responded to, by regulatory mechanisms involving transcription in the nucleus and translation in the cytoplasm. The solution is elegant: there are three key stress sensors/response regulators, IRE1, ATF6, and PERK (Fig. 7), that have one domain in the ER and another in the cytoplasm (Schroder and Kaufman 2005; Ron and Walter 2007). These regulatory systems are complex and involve a variety of inputs, but all involve an auto-regulatory mechanism ( $\mathrm{Li}$ et al. 2010; Wiseman et al. 2010). As misfolded proteins accumulate within the ER lumen they recruit away chaperones that negatively regulate each of the three stress sensors/response regulators. Ensuing changes in their conformations and/or quaternary structure transduce signals across the ER membrane to each protein's cytoplasmic effector domain (Fig. 7) (Schroder and Kaufman 2005; Ron and Walter 2007; Li et al. 2010). As proteostasis problems are fixed, chaperone levels rise and regulatory networks revert to normal status.

Activation of IRE1 is achieved by dimerization and autophosphorylation. Activation of ATF6 is achieved by regulated proteolysis in the Golgi compartment. (Schroder and Kaufman 2005; Ron and Walter 2007). Both proteins regulate the nuclear arm of the UPR. PERK alleviates protein folding problems in the ER in part by a distinct complementary route. Chaperone recruitment from PERK induces dimerization and autophosphorylation. The activated PERK phosphorylates the $\alpha$ subunit of the eukaryotic initiation factor 2 (eIF2 $\alpha)$, which represses translation (Fig. 7) (Schroder and Kaufman
2005; Ron and Walter 2007; Tsaytler et al. 2011) reducing the misfolding and aggregation load on the ER proteostasis system (Schroder and Kaufman 2005; Ron and Walter 2007; Tsaytler et al. 2011).

Toward Amelioration of Lysosomal Storage Diseases in the Secretory Compartment

The lysosome is a central organelle for the degradatory recycling of proteins, glycolipids, glycoproteins and other biomolecules. Lysosomal storage diseases encompass nearly 50 inherited disorders that arise from deficiencies in individual lysosomal degradation enzymes (Sawkar et al. 2002, 2006a). The loss-of-function phenotype is often caused by excessive ER misfolding and ER-associated degradation of these mutant lysosomal enzymes (Fan 2001; Zhao and Grabowski 2002; Futerman and van Meer 2004; Mu et al. 2008b). A promising therapeutic strategy for these diseases is smallmolecule activation of the unfolded protein response (UPR) in patient-derived fibroblasts. UPR activation increases chaperone and folding enzyme concentrations. Hence, these macromolecules function in part by binding to folding intermediates and transition states, thereby resculpting the folding free energy diagrams of proteins so as to maximize the population of the folded ensemble trafficked to the lysosome, while minimizing misfolding and aggregation (Fig. 8) (Mu et al. 2008b). Increasing mutant lysosomal enzyme activity to $>15 \%$ of wild type levels will likely suffice to alleviate most lysosomal storage diseases, and UPR activation exceeds that threshold (Sawkar et al. 2006a; Mu et al. 2008b), restoring mutant enzyme folding, trafficking, and lysosomal activity. The selectivity and specificity of second generation small molecules for activating a specific arm(s) of the UPR is likely to improve dramatically (Tsaytler et al. 2011).

The apparent success of such strategies raises the question: Why is there not excess folding capacity in the ER lumen to begin with? Not only is it metabolically expensive to have excess proteostasis capacity in the ER lumen but limiting this capacity may be necessary to keep viral 


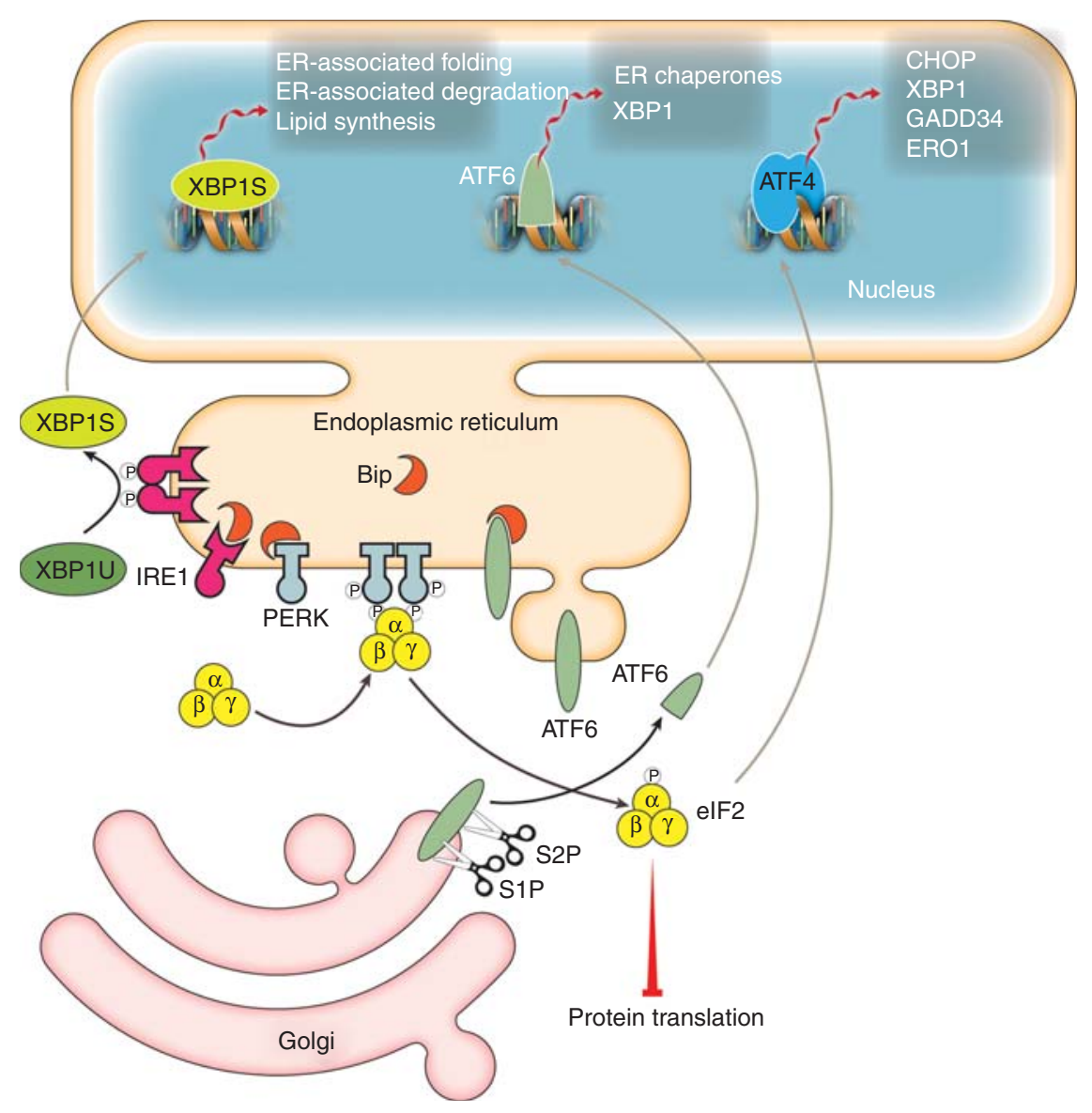

Figure 7. The three arms of the unfolded protein response stress-responsive signaling pathway. Proteostasis network capacity in the endoplasmic reticulum (ER) is matched to the level of newly synthesized proteins passing through the secretory pathway by the activation of intracellular signaling pathways collectively referred to as the unfolded protein response. The unfolded protein response responds to the accumulation of misfolded proteins within the lumen of the endoplasmic reticulum. Accumulation of unfolded proteins activates signaling pathways in the cytosol via the trans-membrane stress sensor proteins IRE1, ATF6, and PERK. Activation of the unfolded protein response results in translational attenuation of protein synthesis and transcriptional activation of genes regulated by the transcription factors XBP1s, ATF4, and ATF6 resulting from the three signaling arms of the unfolded protein response. (Figure adapted from Wiseman et al. [2010] and reprinted, with permission, from Elsevier (C) 2010.)

replication in check and to prevent cancer (Dai et al. 2007; Geller et al. 2007; Cowen et al. 2009; Whitesell and Lindquist 2009). Does UPR activation, then, lead to mechanism-based organismal toxicity? Activation of the unfolded protein response has the potential to alter the physiological balance of the secreted proteome. However, recent whole-cell analysis of fibroblasts treated with UPR activators indicates that the vast majority of the secreted proteome shows unaltered concentrations (based on mass-spectrometry by the spectral counting quantification method) (Mu et al. 2008b). This implies that the vast majority of the secreted proteome shows sufficiently fast folding, thermodynamic stability and slow misfolding and/or aggregation rates to ensure efficient folding at basal settings of the proteostasis network (Powers et al. 
S.L. Lindquist and J.W. Kelly

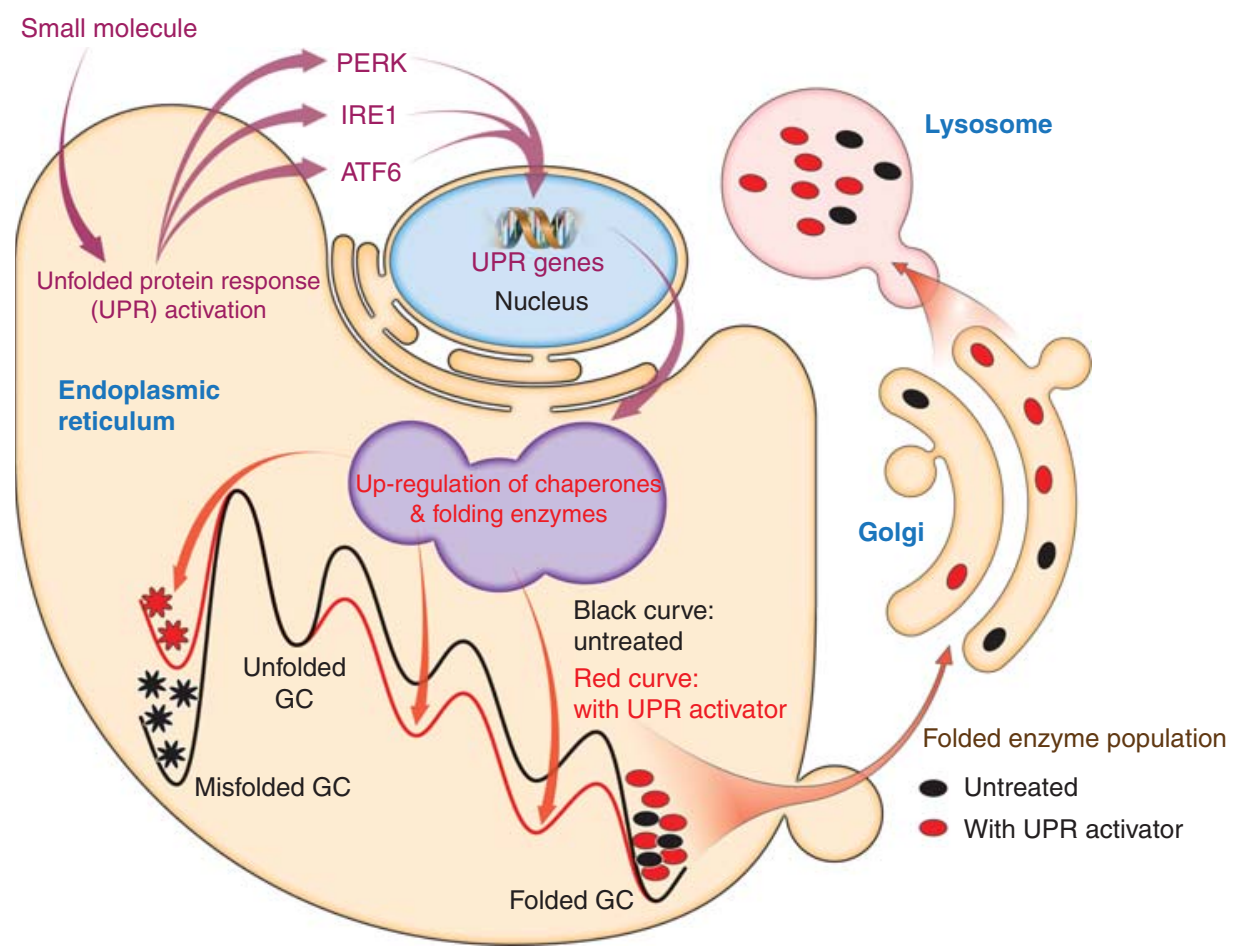

Figure 8. Small molecule activation of the unfolded protein response improves the folding, trafficking, and function of folding compromised secreted proteins. Small molecule activation of one or more arms of the unfolded protein response stress responsive signaling pathway (Fig. 7) in patient-derived fibroblasts partially restores mutant enzyme folding, trafficking and lysosomal activity in the case of mutated, misfolding-prone enzymes associated with distinct lysosomal storage diseases. Chaperones and folding enzymes, increased in concentration in response to activation of the unfolded protein response, bind to folding intermediates and transition states of proteins undergoing folding, resculpting the folding free energy diagrams of misfolding-prone enzymes so as to maximize the population of the folded ensemble, while minimizing misfolding and aggregation-increasing the concentration of properly folded mutant enzyme that can traffic to the acidic environment of the lysosome, the environment in which these enzymes were evolved to function. (Figure adapted from Mu et al. [2008] and reprinted, with permission, from Elsevier (C) 2008.)

2009). Therefore, increasing ER lumenal proteostasis network capacity would have little influence on proteins already folding with high efficiency. In contrast, mutated N-glycosylated lysosomal enzymes fold very inefficiently and will therefore show increased folding, trafficking, and function on UPR activation (Sawkar et al. 2005; Powers et al. 2009). Because the UPR is the natural mechanism for cells to match proteostasis capacity with real-time demand in the secretory pathway, it is reasonable to surmise that modest periodic activation of the UPR will be both effective and generally nontoxic $(\mathrm{Mu}$ et al. 2008b). Emerging evidence suggests that prototypical mechanisms for activating the UPR become muted with aging (Ben-Zvi et al. 2009). Cell nonautonomous stress-responsive signaling is a recent and important revelation (Prahlad et al. 2008; Kirstein-Miles and Morimoto 2010a,b) that we must better comprehend to optimally adapt such pathways for disease intervention.

\section{CFTR and Cystic Fibrosis: A Case Study}

Cystic fibrosis is the most common, deadly, inherited disorder affecting Caucasians in the United States and it is caused by point mutations 
that compromise the folding of the cystic fibrosis transmembrane conductance regulator (CFTR), a chloride channel protein of the ABC transporter category that resides in the plasma membranes of many tissues including the lungs and the gastrointestinal tract (Riordan 1999, 2008). The most common mutation, $\Delta$ F508, leads to substantial misfolding and ER-associated degradation early in the secretory pathway, resulting in insufficient $\mathrm{Cl}^{-}$channel activity in the lung (Qu et al. 1997; Riordan 1999, 2008).
Unlike lysosomal storage diseases, where misfolding occurs in the ER lumen itself, CFTR is a multipass transmembrane protein and the critical F508 residue is in one of its cytosolic nucleotide binding domains (Qu et al. 1997; Sawkar et al. 2005, 2006a,b). Antibodies recognizing an epitope of $\Delta$ F508 CFTR and wt CFTR that is always unfolded were used in immunoprecipitation to define the proteostasis network that interacts with wt and $\Delta$ F508 CFTR (Fig. 9) (Wang et al. 2006).
A

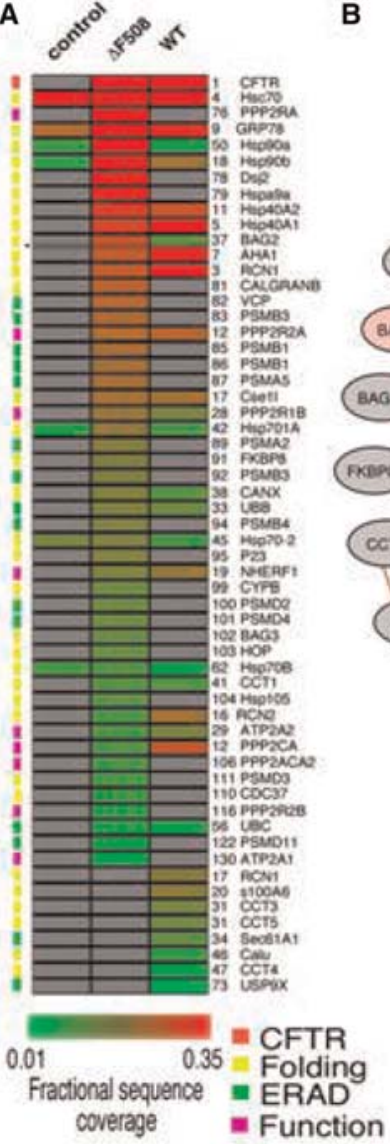

B

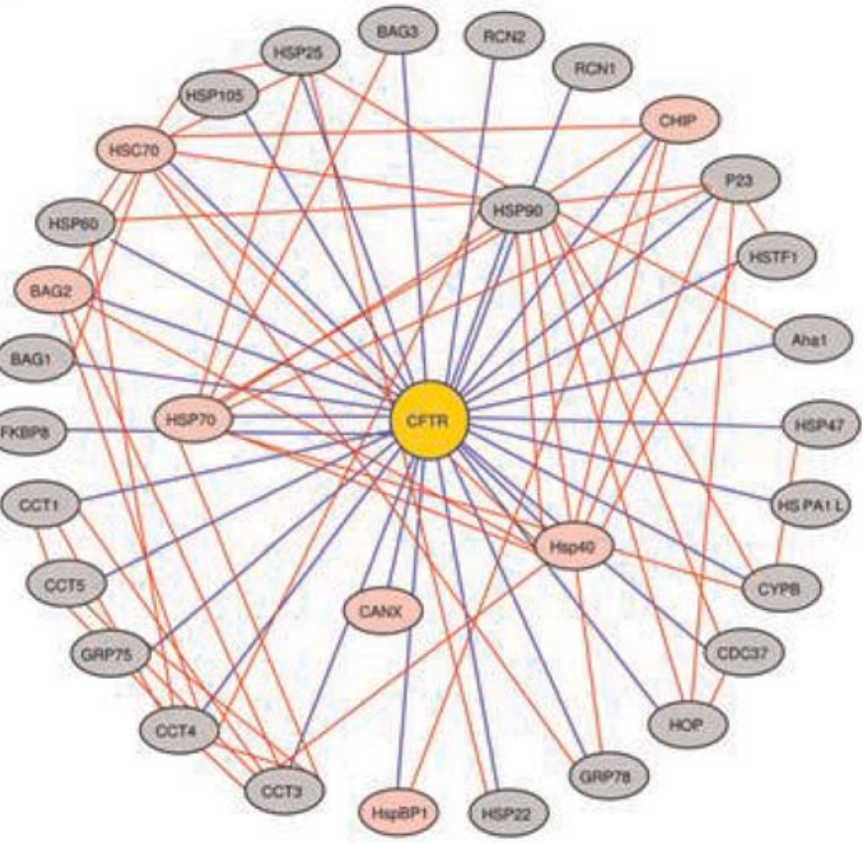

C

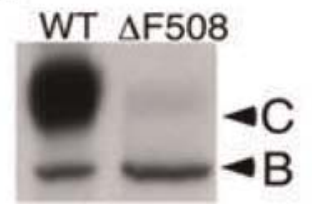

Figure 9. Characterization of proteostasis network components used by the client protein cftr using immunoisolation followed by mass spectrometry. The cystic fibrosis transmembrane conductance regulator (CFTR) interactome (panels $A$ and $B$ ) was characterized by immunoisolating both wild type and mutant $(\Delta$ F508) CFTR followed by characterization of the interacting proteins by MudPIT mass spectrometry. A $\Delta$ F508 CFTR folding intermediate in the cytosol appears to be sequestered by the Hsp90 chaperone-Aha1 cochaperone complex leading to endoplasmic reticulum-associated degradation and poor secretion (Panel C: note lack of C band reflecting CFTR on plasma membrane). Reducing the concentration of Ahal enhances the folding of $\Delta$ F508 CFTR by altering the proteostasis network in such a fashion that it can now more efficiently fold $\Delta$ F508 CFTR. Figure kindly provided by William E. Balch. 
The $\Delta$ F508 CFTR folding intermediate in the cytosol appears to be strongly sequestered by the Hsp90 chaperone-Aha1 cochaperone complex (Wang et al. 2006). Attempts to restore the CFTR proteostasis network with siRNA against Aha1, restored partial folding, trafficking and function (Wang et al. 2006). Ahal siRNA may function by adjusting the Hsp90Ahal folding cycle period to match the altered folding kinetics shown by $\Delta$ F508 CFTR (Wang et al. 2006). Alternatively, or in addition, Ahal siRNA could alter the affinity of the tripartite interaction between Hsp90, Ahal, and the $\Delta$ F508 CFTR nucleotide binding domain 1 misfolded intermediate (Wang et al. 2006; Koulov et al. 2010).

Separate pharmacological and genetic experiments found that reducing histone deacetylase 7 activity restores $\Delta$ F508 CFTR proteostasis in patient-derived cells (Hutt et al. 2010). Hsp90 is regulated by histone acetyl transferases and histone deacetylases (HDACs) and plays a role in proteolysis as well as folding. Thus, HDAC effects on Hsp90-Ahal interactions might directly to influence $\Delta$ F508 CFTR proteostasis (Wang et al. 2006). Acetylation could also regulate components of the proteostasis network that indirectly affect $\Delta$ F508 CFTR proteostasis (Wang et al. 2006). Alternatively, or in addition, HDAC inhibitors might alter histone acetylation influencing the epigenome and transcription of the CFTR proteostasis network (Hutt et al. 2010). In addition, HDAC7 inhibition may reduce the transcription of $\Delta$ F508 CFTR, increasing the proteostasis network capacity by decreasing the folding load on the network (Hutt et al. 2010).

Compounds of Unknown Mechanism that Likely Influence the Proteostasis Network Alleviate the Phenotypes of Type II Diabetes and Metabolic Syndrome

Proteostasis deficiencies arising from ER folding, trafficking or degradation defects may be at the heart of type II diabetes and metabolic syndrome. In the leptin-deficient ob/ob mouse model of obesity and insulin resistance, complex disease-associated phenotypes showed are alleviated by enhancing ER folding capacity with the small molecule "chemical chaperones" taurine-conjugated ursodeoxycholic acid and 4-phenylbutyrate (4-PBA) (Ozcan et al. 2006). Oral administration reversed hyperglycemia, increased glucose tolerance, improved insulin receptor signaling and decreased stress inside the ER in response to protein misfolding. Notably, the fatty liver phenotype in the liver also resolved with treatment (Ozcan et al. 2006). The "chemical chaperone" category of small molecules has been used as a catch-all for compounds of unknown mechanism of action, like 4-PBA (Liu et al. 2004), and compounds that clearly influence folding by altering the physical chemistry of folding. These osmolytes must be used at very high concentrations to achieve efficacy, but such high concentrations are often observed in normal physiological responses to proteostasis stress (Singer and Lindquist 1998). Given the striking influence of chemical chaperones on diseases of complex etiology, it is imperative to better discern their beneficial mechanism(s) of action and possible mechanisms of toxicity.

Prolonging the Unfolded Protein Response and Translational Attenuation to Prevent Pancreatic $\beta$-Cell Loss Associated with Diabetes

Phosphorylation of eIF2 $\alpha$, resulting from activation of the PERK arm of the UPR (Fig. 10), generally halts translation as discussed above (Schroder and Kaufman 2005; Ron and Walter 2007). Phosphorylated eIF2 $\alpha$ also selectively promotes translation of the transcription factor ATF4, which targets stress-responsive genes, including the transcription factor CHOP. This, in turn, can promote apoptosis or programmed cell death. One of CHOP's target genes is the regulatory subunit GADD34 or PPP1R15A, which binds to the catalytic domain of protein phosphatase 1 (PP1). The heterodimer made of the protein phosphatase 1 catalytic domain and GADD34 regulatory domain selectively dephosphorylates eIF2 $\alpha$ (Fig. 10). This attenuates phosphorylated eIF $2 \alpha$ signaling, facilitating restoration of ribosomal translation 


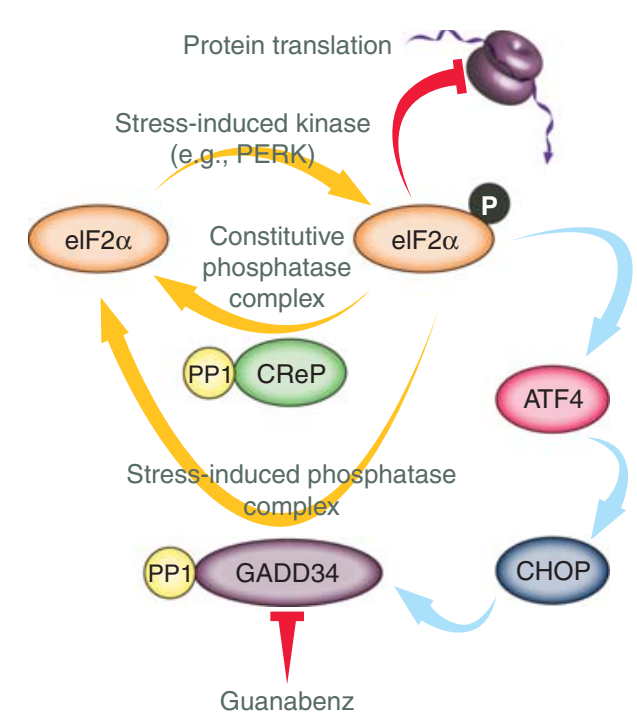

Figure 10. Prolonging an emergent property of stress responsive signaling. Guanabenz prolongs eIF $2 \alpha-$ mediated translational attenuation associated with activation of the PERK arm of the unfolded protein response, enhancing proteostasis by decreasing the protein load on the proteostasis network and increasing the folding enzyme and chaperone-cochaperone stoichiometry relative to that of the client proteins. Guanabenz inhibits the GADD34-mediated negative feedback loop by direct binding to GADD34, the regulatory subunit of the phosphatase, preventing its association with protein phosphatase 1 (PP1), the catalytic subunit of the phosphatase. Importantly, guanabenz does not inhibit the constitutive eIF $2 \alpha$ phosphatase CReP-PP1 heterodimer, thus translational attenuation ultimately ceases, just more slowly.

following ER stress, providing a negative feedback loop in the PERK stress-responsive signaling arm (Wiseman et al. 2010; Genereux and Wiseman 2011).

Several lines of evidence show that PERK signaling is critical for maintaining ER proteostasis in pancreatic $\beta$-cells expressing high levels of insulin (Volchuk and Ron 2010). Modulation of PERK signaling may alleviate ER stress associated with increased insulin production or misfolding-prone mutant insulin production. Consistent with this hypothesis, in the Akita diabetic mouse model guanabenz protects cells against ER stress induced by the overexpression of a destabilized mutant insulin protein (Tsaytler et al. 2011; Wiseman and
Kelly 2011). Guanabenz binds the GADD34 regulatory phosphatase subunit, preventing GADD34 regulatory phosphatase subunit•PP1 catalytic subunit heterodimer formation required for its phosphatase activity (Fig. 10). Thus, guanabenz represents a novel approach for inhibiting an emergent activity of a stressresponsive signaling pathway - the phosphatase activity emerging from GADD34 $\cdot \mathrm{PP} 1$ heterodimer formation resulting from PERK activation, which represents a key component of the negative feedback loop of the PERK pathway that turns signaling off (Tsaytler et al. 2011; Wiseman and Kelly 2011). Importantly guanabenz does not bind to the regulatory subunit CReP, thus the CReP•PP1 constitutive phosphatase remains functional to dephosphorylate eIF2 $\alpha$ (Fig. 10). Therefore, guanabenz prolongs PERK signaling and translational attenuation (Schroder and Kaufman 2005), which is eventually turned off by the CReP.PP1 phosphatase. It will be interesting to see whether prolonged PERK signaling, enabled by guanabenz treatment, is sufficient to restore mutant lysosomal enzyme proteostasis (Sawkar et al. 2006a) and proteostasis in other loss-of-function diseases resulting from excessive ER misfolding and ER-associated degradation. Guanabenz also has the potential to modulate translational attenuation in response to other cellular stresses, such as oxidative stress that activates alternative eIF2 $\alpha$ kinases (Harding et al. 2003; Wek et al. 2006). If this effect is observed, prolonging PERK signaling has the potential to enhance cellular survival in response to a variety of stresses.

\section{Proteasome Inhibitors and the Heat Shock Response}

Proteasome inhibitors induce the unfolded protein response and the heat shock response stress-responsive signaling pathways, apparently inducing apoptosis in plasma cell dyscrasias like multiple myeloma and light chain amyloid disease (Richardson Paul 2004; Richardson Paul and Mitsiades 2005; Mu et al. 2008b; Orlowski and Kuhn 2008; Zhu et al. 2010). Although much needs to be learned about the mechanism by which these compounds function in cancer, 
it could be the case that infrequent application of proteasome inhibitors could protect an organism from chronic stress by enhancing basal proteostasis network capacities of subcellular compartments. Because such compounds also induce the accumulation of misfolded and aggregated proteins, such an approach should be explored with caution.

\section{Posttranslational Up-Regulation of ER Proteostasis Network Capacity by Increasing $\mathrm{ER} \mathrm{Ca}^{2+}$ Concentration}

Several chaperones and folding enzymes residing in the ER, including calnexin, calreticulin, and Bip, are regulated by $\mathrm{ER} \mathrm{Ca}^{2+}$ binding with dissociation constants in the $10^{2}-10^{3} \mu \mathrm{M}$ range (Fig. 11) (Baksh and Michalak 1991). It has been reported by many groups that ER $\mathrm{Ca}^{2+}$ concentrations are suppressed in individuals with both loss- and gain-of-function misfolding/aggregation diseases (Korkotian et al. 1999; Lloyd-Evans et al. 2003; Futerman and van Meer 2004; Pelled et al. 2005). Small molecules that inhibit $\mathrm{Ca}^{2+}$-induced $\mathrm{Ca}^{2+}$ release by targeting the L-type $\mathrm{Ca}^{2+}$ channels in the plasma membrane and/or antagonize the ryanodine receptors that mediate efflux of $\mathrm{Ca}^{2+}$ from the ER improve the folding, lysosomal trafficking and lysosomal function of mutated enzymes associated with lysosomal storage diseases (Mu et al. 2008a; Ong et al. 2010). Diltiazem is a particularly potent molecule in this regard, as it inhibits both L-type $\mathrm{Ca}^{2+}$ channels and the ryanodine $\mathrm{Ca}^{2+}$ efflux channel harbored in the ER membrane, restoring L444P glucocerebrosidase activity back to approximately $20 \%$ of wild type lysosomal activity ( $\mathrm{Mu}$ et al. 2008a; Ong et al. 2010). This approach was shown to be useful in patient-derived cells from other lysosomal storage diseases (Ong et al. 2010). Although the exact mechanism by which $\mathrm{Ca}^{2+}$ binds to and regulates the function of calnexin, calreticulin, and Bip (the ER Hsp70) is currently unknown, understanding these molecular details will undoubtedly lead to new approaches for posttranslational regulation of the ER proteostasis network (Williams 2006; Brockmeier et al. 2009). Diltiazem is known to penetrate the brain and has been

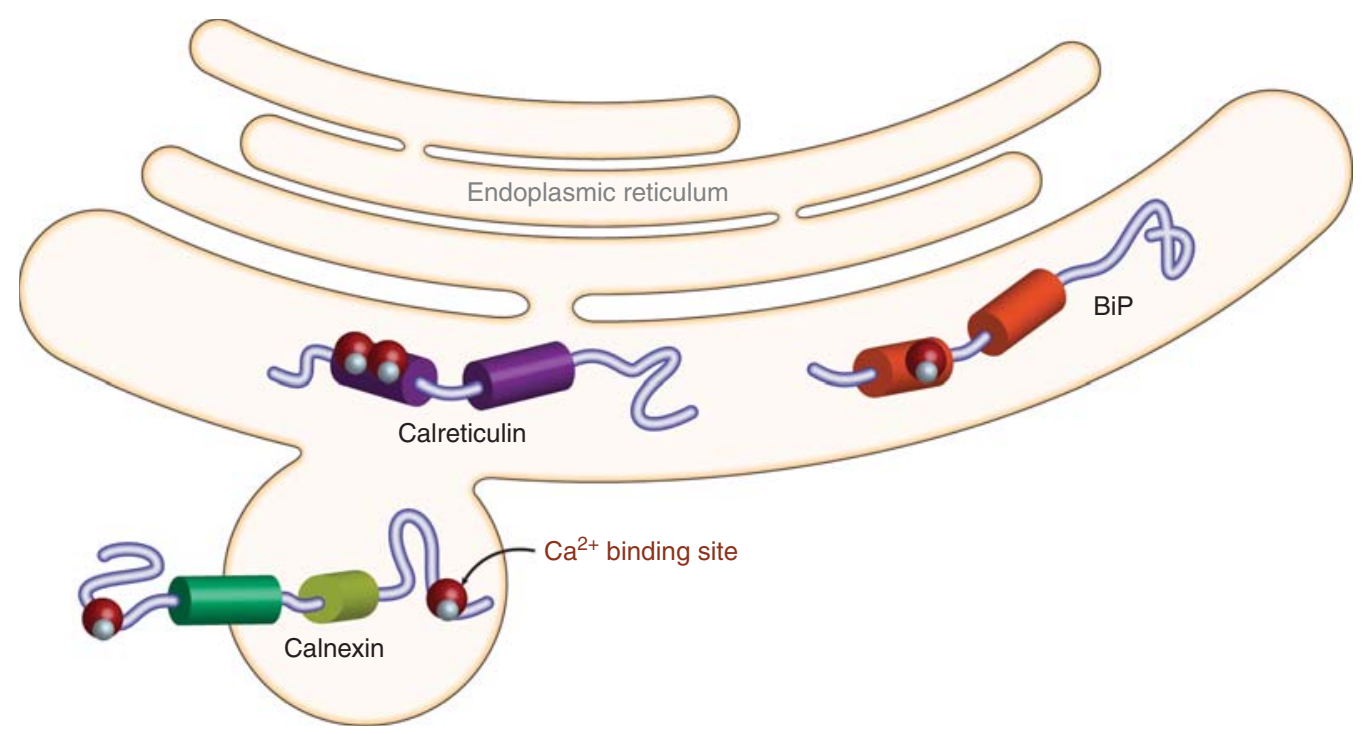

Figure 11. Endoplasmic reticulum chaperones appear to be regulated by calcium binding —altering ER calcium levels to regulate chaperone function. Endoplasmic reticulum chaperones including calnexin, calreticulin, and Bip (Hsp70) have $\mathrm{Ca}^{2+}$ binding sites that appear to be important for regulating the function of these critical chaperones. (Figure kindly provided by Derrick Ong.) 
Approaches for Adapting Proteostasis

used safely for over 30 years to reduce high blood pressure, demonstrating that compounds that adapt proteostasis by chronically increasing ER $\mathrm{Ca}^{2+}$ concentrations are likely to be safe and effective drugs (Glasser 2006).

Activating Proteolytic Degradation by the Lysosome to Reestablish Proteostasis in a Gain-of-Toxic-Function Aggregation Disease

Mutations in $\alpha 1$-antitrypsin, a glycoprotein secreted by the liver, that compromise its folding and secretion can lead to emphysema (loss-of-function of neutrophil elastase inhibition in the lung) or hepatic fibrosis or hepatocellular carcinoma (Lomas and Perlmutter 2010; Perlmutter 2011). Degeneration of the liver is caused by aggregation and ER accumulation of the so-called $\mathrm{Z}$ variant (Glu342Lys) of $\alpha 1$-antitrypsin (Lomas and Perlmutter 2010; Perlmutter 2011). Because macroautophagic degradation of the ER-localized aggregates of the $\mathrm{Z}$ variant of $\alpha 1$-antitrypsin is known to be operational and important, the activation of autophagy was explored as a means of preventing hepatic fibrosis and/or carcinogenesis associated with $\alpha 1$-antitrypsin $Z$ aggregationmediated proteotoxicity (Hidvegi et al. 2010; Perlmutter 2011). The autophagy-enhancing drug carbamazepine decreased the hepatic load of the $\mathrm{Z}$ variant of $\alpha 1$-antitrypsin and hepatic fibrosis in a murine model (Hidvegi et al. 2010; Perlmutter 2011). Mechanistic studies indicate that carbamazepine increases both proteasomal and autophagic degradation of the $\mathrm{Z}$ variant of $\alpha 1$-antitrypsin. It is interesting that disposal of the $Z$ variant of $\alpha 1$-antitrypsin cannot be accounted for fully in terms of a classical macroautophagy pathway or by proteosomal degradation (Hidvegi et al. 2010; Perlmutter 2011). That rapamycin does not increase the degradation of the $\mathrm{Z}$ variant of $\alpha 1$-antitrypsin implies that carbamazepine likely functions through a TOR-independent autophagy activation pathway. Thus, carbamazepine might be considered for clearing cellular aggregates in other degenerative diseases wherein protein aggregates cause proteotoxicity.

\section{CHEMICAL STRATEGIES TO AMELIORATE MISFOLDING AND AGGREGATION DISEASES}

Pharmacologic Chaperones to Prevent the Misfolding and Excessive Degradation of Lysosomal Enzymes Folded in the Secretory Pathway

Increased mutant lysosomal enzyme folding, trafficking, and function can be realized at the expense of excessive mutant lysosomal enzyme ER misfolding and ER-associated degradation by using ER-permeable active-site-directed pharmacologic chaperones to stabilize the folded state of the mutant lysosomal enzymes in the ER (Fig. 12) (Sawkar et al. 2002, 2006a; Fan 2003; Yu et al. 2007a). Mutant lysosomal enzymes have to fold at $\mathrm{pH} 7$ in the ER, yet they have evolved to function around pH 5 in the lysosome. Thus, pharmacologic chaperones that bind strongly $\mathrm{pH} 7$, but weakly at $\mathrm{pH} 5$, are highly desirable to avoid inhibition of the increased concentration of mutant enzyme in the lysosome resulting from pharmacologic chaperoning ( $\mathrm{Yu}$ et al. 2007a). Pharmacologic chaperone inhibition of the increased pool of mutant lysosomal enzyme in the ER is also minimized by the lysosomal storage of the substrate (after which these diseases are named), which leads to a very high concentration of the substrate in the lysosome, which outcompetes the pharmacologic chaperone/enzyme inhibitor for binding to the mutant lysosomal enzyme.

Many of the clinically important $\alpha$-galactosidase A mutants causing the lysosomal storage disorder, Fabry disease, were shown to be folding and trafficking mutants (Ishii et al. 1993), before this was explored as a possibility in Gaucher's disease. Galactose administration increased Q279E $\alpha$-galactosidase A residual activity in patient-derived cells, thus galactose was shown to be first active-site-directed pharmacologic chaperone for a lysosomal storage disease. Galactose administration $(1 \mathrm{~g} / \mathrm{kg}$ body weight) every other day proved to be effective enough for a Fabry disease patient harboring the G328R variant to avoid a heart transplant (Frustaci et al. 2001). An active-site-directed pharmacologic chaperone for $\alpha$-galactosidase 
S.L. Lindquist and J.W. Kelly

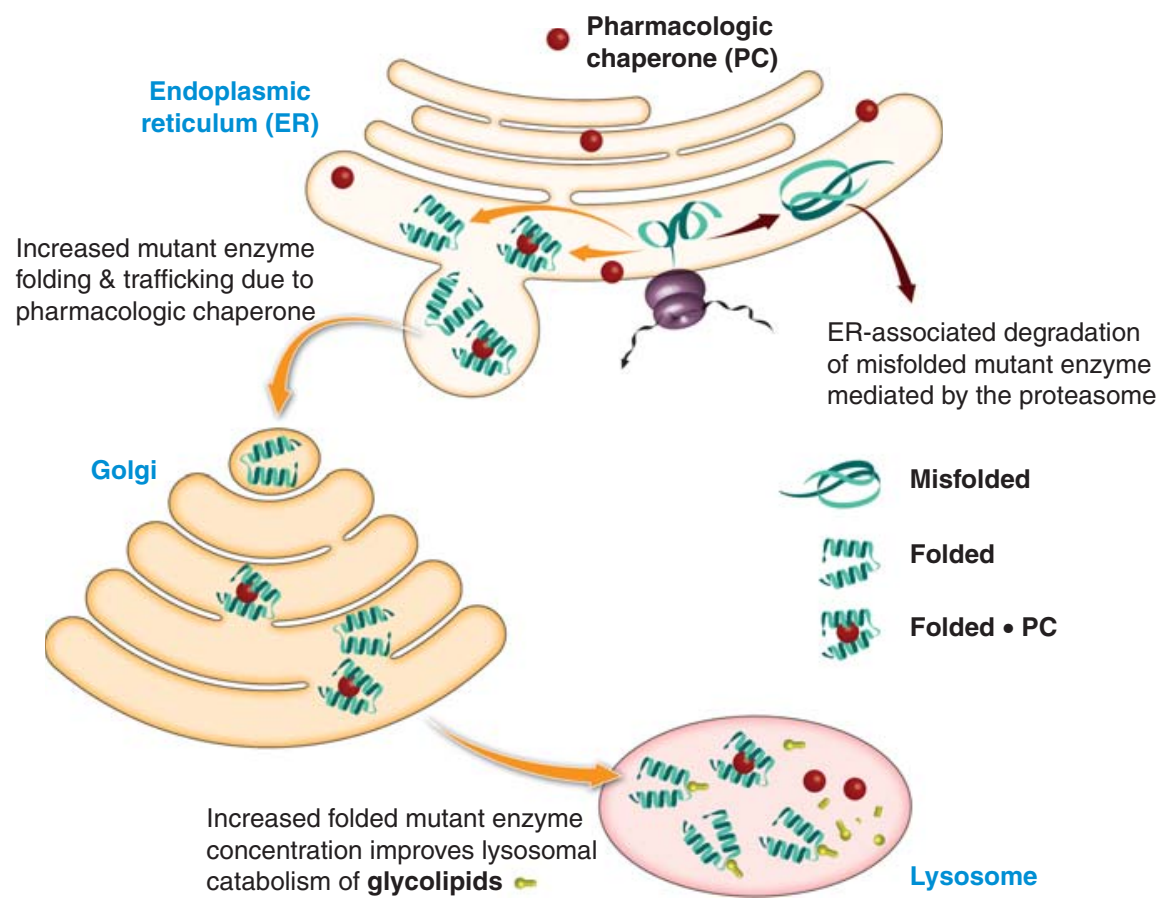

Figure 12. Pharmacologic chaperone strategy to enhance the folding trafficking and function of misfoldingprone proteins. Pharmacologic chaperone binding stabilizes the folded state of mutant proteins, increasing the population of the folded mutant enzyme ensemble in the endoplasmic reticulum that can engage the trafficking receptor and be trafficked to the lysosome, increasing the mutant enzyme concentration in the lysosome. Mutant enzyme inhibition in the lysosome can be minimized by creating pharmacologic chaperones that bind with much higher affinity at $\mathrm{pH} 7$ than they do at $\mathrm{pH} 5$ - the operating $\mathrm{pH}$ of the lysosome.

A is now in phase II/III clinical trials for Fabry disease by Amicus Pharmaceuticals (Fan et al. 1999; Asano et al. 2000; Fan 2003).

Several glucocerebrosidase variants associated with Gaucher's disease have been shown to be amenable to active-site-directed pharmacologic chaperoning in patient-derived cell lines (Sawkar et al. 2002, 2005, 2006a,b; Lin et al. 2004; Alfonso et al. 2005; Chang et al. 2006; Compain et al. 2006; Steet et al. 2006; Yu et al. 2006, 2007b). All of the glucocerebrosidase mutants that favorably respond to pharmacologic chaperoning harbor mutations in the active site domain, whereas the L444P mutation, located in the Ig-like domain of glucocerebrosidase, (Dvir et al. 2003; Lieberman et al. 2007) is not amenable to pharmacologic chaperoning when treated identically. Mutations in domains remote from the active site domain may be subject to misfolding, despite binding-induced stabilization by the pharmacologic chaperone to the active site domain, especially if the domains are not thermodynamically coupled. We have since shown that even mutations not amenable to pharmacologic chaperoning can be chaperoned when the capacity of the proteostasis network is increased to generate a higher concentration of folded state or near-folded state for the active-sitedirected small molecule pharmacologic chaperones to bind to (Mu et al. 2008b).

\section{Small Molecule Kinetic Stabilizers Prevent Transthyretin Amyloidogenesis Leading to Postmitotic Tissue Degeneration}

Rate-limiting transthyretin tetramer dissociation, monomer misfolding and thermodynamically favorable misassembly into a spectrum of aggregate types, including amyloid fibrils, is 
genetically and pathologically linked to several degenerative diseases that selectively compromise postmitotic tissue (Fig. 13) (Colon and Kelly 1992; Lai et al. 1996; Liu et al. 2000; Jiang et al. 2001b; Hammarstrom et al. 2003; Hurshman et al. 2004; Foss et al. 2005; Johnson et al. 2005b; Sekijima et al. 2005). These so-called amyloid diseases include familial amyloid polyneuropathy ( $\approx 10,000$ patients worldwide) (Andrade 1952), wherein dissociation of destabilized tetramers composed of one of over 100 destabilized variants of transthyretin leads to amyloidogenesis and the degeneration of the peripheral and autonomic nervous systems (McCutchen et al. 1995; Hammarstrom et al. 2002; Sekijima et al. 2005; Hurshman Babbes et al. 2008). In senile systemic amyloidosis (affects 15\% of humans over the age of 70), extracellular dissociation of the wild type transthyretin tetramer followed by monomer misfolding and amyloidogenesis leads to selective degeneration of the heart (Cornwell et al. 1988; Westermark et al. 1990). Heterozygotes expressing transthyretin tetramers comprised of certain mutant and wild type subunits, on tetramer dissociation and misfolded monomer amyloidogenesis are subjected to familial amyloid cardiomyopathy, a very aggressive disease affecting, among other populations, $4 \%$ of Africans harboring the Val122Ile mutation (Jacobson et al. 1997; Jiang et al. 2001a; Yamashita et al. 2005).

The weaker dimer-dimer interface of tetrameric transthryetin comprises two thyroxine binding sites that are unoccupied in humans (Blake et al. 1978; Purkey et al. 2001; Foss et al. 2005; Johnson et al. 2005b). Occupancy of one of these binding sites with a kinetic stabilizer, a small molecule that binds to transthyretin with high affinity and lacks thyroid agonist or antagonist activity, is sufficient to make the tetramer dissociation barrier insurmountable

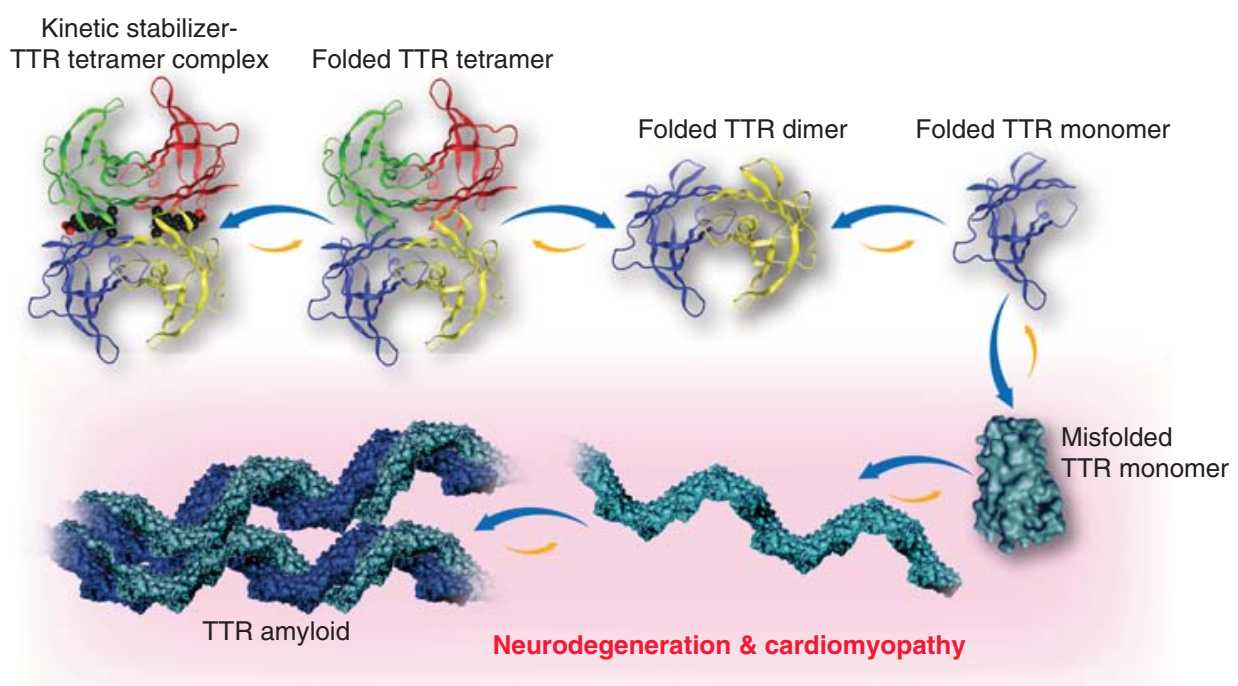

Figure 13. Kinetic stabilizer strategy to prevent the misfolding and aggregation of transthyretin into amyloid resulting in the degradation of postmitotic tissue. Rate-limiting transthyretin (TTR) tetramer dissociation proceeding through the dimer shown, monomer misfolding and thermodynamically favorable misassembly into a spectrum of aggregate types, including amyloid fibrils, is genetically and pathologically linked to several degenerative diseases that selectively compromise postmitotic tissue, including the heart and the nervous system. Occupancy of one of the thyroxine binding sites at the weaker dimer-dimer interface with a small molecule kinetic stabilizer (shown in black and red CPKview) is sufficient to make the tetramer dissociation barrier insurmountable under physiological conditions, precluding amyloidogenesis, while still allowing tetrameric TTR to function. 


\section{S.L. Lindquist and J.W. Kelly}

under physiological conditions, precluding amyloidogenesis (Miroy et al. 1996; Baures et al. 1998, 1999; Oza et al. 1999, 2002; Klabunde et al. 2000; Petrassi et al. 2000, 2005; Green et al. 2003; Hammarstrom et al. 2003; Razavi et al. 2003, 2005; Adamski-Werner et al. 2004; Miller et al. 2004; Purkey et al. 2004; Green et al. 2005; Johnson et al. 2005a,b, 2008a,b, 2009; Wiseman et al. 2005; Sekijima et al. 2006; Tojo et al. 2006; Choi et al. 2010a,b; Connelly et al. 2010). Tafamidis, a benzoxazole-based transthyretin kinetic stabilizer discovered in academia (Razavi et al. 2003) and developed by FoldRx Pharmaceuticals, showing a $2 \mathrm{nM}$ dissociation constant from transthyretin (Razavi et al. 2003), has

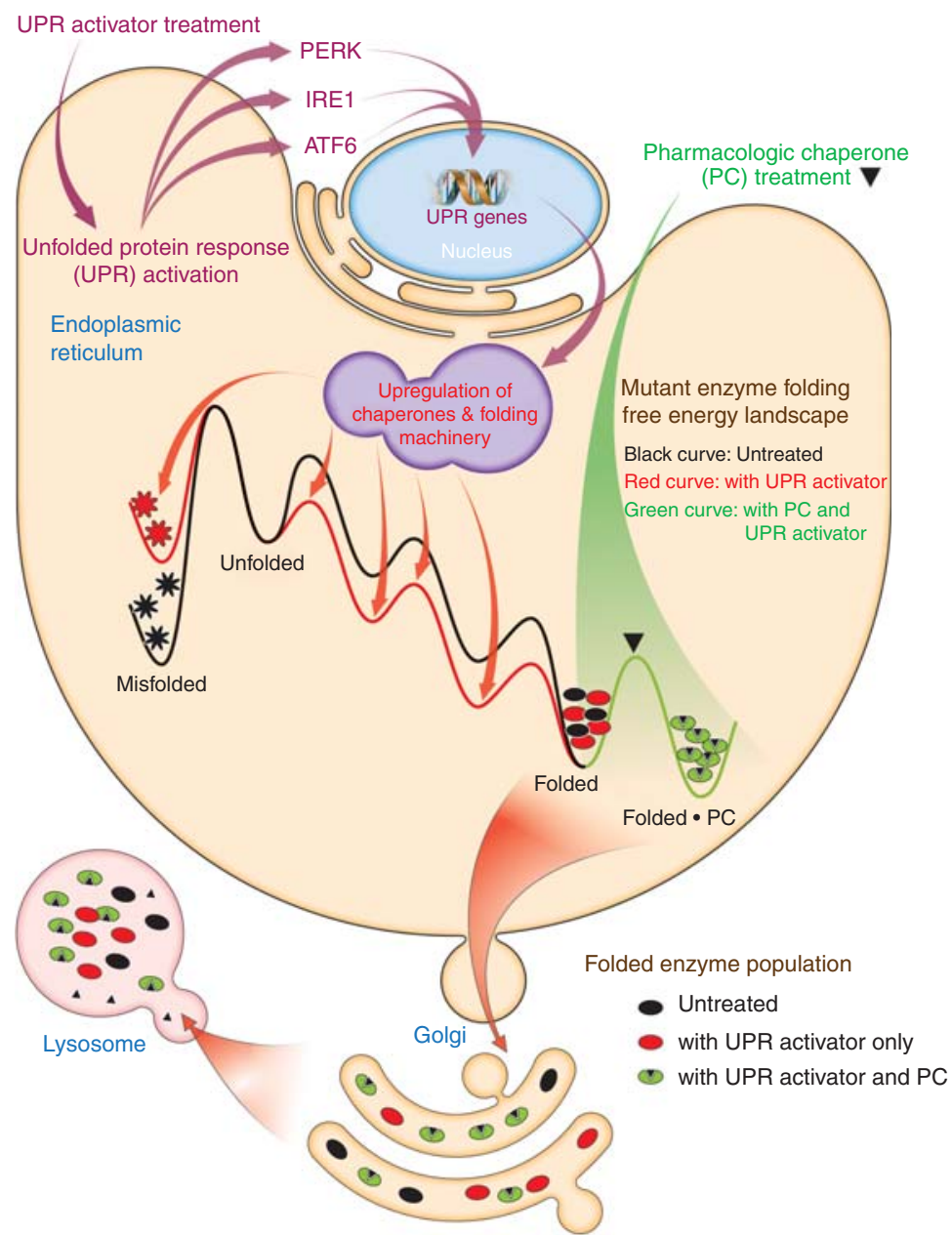

Figure 14. Mechanistically distinct manipulators of the proteostasis network can result in additive or synergistic rescue of proteostasis. Coapplication of a small molecule unfolded protein response activator and a pharmacologic chaperone affords a synergistic rescue of mutant lysosomal enzyme proteostasis. A small molecule unfolded protein response activator resculpts the folding free energy diagram of a mutant enzyme and "pushes" more misfolding-prone mutant enzyme toward the native conformational ensemble, while the pharmacologic chaperone binds to the native state of a mutant lysosomal enzyme, stabilizing it and therefore increasing the concentration of the mutant enzyme•pharmacologic chaperone complex, effectively "pulling" more of the mutant protein toward the native state. Treatment of patient-derived cells with a pharmacologic chaperone and an unfolded protein response activator leads to more folding, trafficking and mutant enzyme function than the sum of the individual treatments. 
recently successfully completed a phase II/III trial against Val30Met-associated familial amyloid polyneuropathy. That this kinetic stabilizer halts the progression of neurodegeneration in these Val30Met-wt TTR heterozygotes, makes Tafamidis the first drug that alters the underlying etiology of a human amyloid disease. More importantly, this success provides strong support for the amyloid hypothesis - the notion that the process of transthyretin amyloidogenesis causes these degenerative diseases. There are now substantial efforts in multiple pharmaceutical companies applying pharmacologic chaperone and kinetic stabilizer approaches to a spectrum of human amyloid diseases, including those derived from the aggregation of intrinsically disordered proteins.

\section{SYNERGY RESULTING FROM THE COAPPLICATION OF CHEMICAL AND BIOLOGICAL STRATEGIES TO AMELIORATE MISFOLDING AND AGGREGATION DISEASES}

The Use of Mechanistically Distinct

Proteostasis Regulators or a Proteostasis Regulator and a Pharmacologic Chaperone to Improve Loss-of-Function Misfolding

Diseases

Enhancing the capacity of the proteostasis network through unfolded protein response activation is envisioned to minimize protein misfolding and aggregation, enabling more protein to reach the native state through rescuplting of its free energy profile (Fig. 8) (Schroder and Kaufman 2005; Ron and Walter 2007; Mu et al. 2008b; Wiseman et al. 2010). In the case of mutant lysosomal enzymes, unfolded protein response activation is thought to push more mutant enzyme toward the native conformation (Fig. 8) (Mu et al. 2008b). Thus, coapplication of an unfolded protein response activator and a pharmacologoic chaperone that binds to the native state of a mutant lysosomal enzyme and "pulls" more of the mutant enzyme to the native state has been shown to afford the best mutant lysosomal enzyme proteostasis rescue observed to date (Fig. 14) ( $\mathrm{Mu}$ et al. 2008b). We propose that numerous loss-of-function diseases will be treated in the future using either a proteostasis network activator and a pharmacologic chaperone or two mechanistically distinct proteostasis network activators (Mu et al. 2008b).

\section{SUMMARY AND PERSPECTIVE}

The real time adaptation of proteostasis network capacity by the stress-responsive signaling pathways is the natural means by which challenges to the proteome are met. Thus, it is our hypothesis that periodic stimulation of the stress-responsive signal pathways, e.g., once a week, may represent a safe and effective mechanism for intervention in loss- and/or gainof-function misfolding and/or aggregation diseases. Small molecules to activate or prolong activation of stress-responsive signaling pathways are being discovered at an impressive rate for applications in specific diseases where stressresponsive signaling has become muted. We predict that these diseases will be treated in the future by combination therapy. One of the molecules is envisioned to be a stress-responsive signaling pathway activator or the like, whereas the other is expected to bind to and stabilize the misfolding-prone or aggregation-predisposed protein. In some scenarios, it may be best to use two mechanistically distinct proteostasis regulators.

\section{REFERENCES}

Adamski-Werner SL, Palaninathan SK, Sacchettini JC, Kelly JW. 2004. Diflunisal analogues stabilize the native state of transthyretin. Potent inhibition of amyloidogenesis. J Med Chem 47: 355-374.

Akerfelt M, Morimoto RI, Sistonen L. 2010. Heat shock factors: Integrators of cell stress, development and lifespan. Nat Rev Mol Cell Biol 11: 545-555.

Albanese V, Reissmann S, Frydman J. 2010. A ribosomeanchored chaperone network that facilitates eukaryotic ribosome biogenesis. J Cell Biol 189: 69-81.

Alfonso P, Pampin S, Estrada J, Rodriguez-Rey JC, Giraldo P, Sancho J, Pocovi M. 2005. Miglustat (NB-DNJ) works as a chaperone for mutated acid $\beta$-glucosidase in cells transfected with several Gaucher disease mutations. Blood Cells Molecules Diseases 35: 268-276.

Andrade C. 1952. A peculiar form of peripheral neuropathy Familiar atypical generalized amyloidosis with special involvement of the peripheral nerves. Brain 75: 408-427. 
Anfinsen CB. 1973. Principles that govern the folding of protein chains. Science 181: 223-230.

Arantes-Oliveira N, Apfeld J, Dillin A, Kenyon C. 2002. Regulation of life-span by germ-line stem cells in Caenorhabditis elegans. Science 295: 502-505.

Arias E, Cuervo AM. 2011. Chaperone-mediated autophagy in protein quality control. Curr Opin Cell Biol 23: 184189.

Asano N, Ishii S, Kizu H, Ikeda K, Yasuda K, Kato A, Martin OR, Fan J-Q. 2000. In vitro inhibition and intracellular enhancement of lysosomal $\alpha$-galactosidase A activity in Fabry lymphoblasts by 1-deoxygalactonojirimycin and its derivatives. Eur J Biochem 267: 4179-4186.

Auluck PK, Chan HY, Trojanowski JQ, Lee VM, Bonini NM. 2002. Chaperone suppression of $\alpha$-synuclein toxicity in a Drosophila model for Parkinson's disease. Science 295: 809-810.

Bagatell R, Whitesell L. 2004. Altered Hsp90 function in cancer: A unique therapeutic opportunity. Molecular Cancer Therapeutics 3: 1021-1030.

Baksh S, Michalak M. 1991. Expression of calreticulin in Escherichia-coli and identification of its $\mathrm{Ca}^{2+}$ binding domains. J Biol Chem 266: 21458-21465.

Balch WE, Morimoto RI, Dillin A, Kelly JW. 2008. Adapting proteostasis for disease intervention. Science 319: $916-$ 919.

Baures PW, Peterson SA, Kelly JW. 1998. Discovering transthyretin amyloid fibril inhibitors by limited screening. Bioorg Med Chem 6: 1389-1401.

Baures PW, Oza VB, Peterson SA, Kelly JW. 1999. Synthesis and evaluation of inhibitors of transthyretin amyloid formation based on the nonsteroidal anti-inflammatory drug flufenamic acid. Bioorg Med Chem 7: 1339-1347.

Behrends C, Langer Carola A, Boteva R, Bottcher Ulrike M, Stemp Markus J, Schaffar G, Rao Bharathi V, Giese A, Kretzschmar H, Siegers K, et al. 2006. Chaperonin TRiC promotes the assembly of polyQ expansion proteins into nontoxic oligomers. Mol Cell 23: 887-897.

Ben-Zvi A, Miller EA, Morimoto RI. 2009. Collapse of proteostasis represents an early molecular event in Caenorhabditis elegans aging. Proc Natl Acad Sci 6: 1-6.

Bieschke J, Zhang Q, Bosco DA, Lerner RA, Powers ET, Wentworth P Jr, Kelly JW. 2006. Small molecule oxidation products trigger disease-associated protein misfolding. Acc Chem Res 39: 611-619.

Blake CCF, Geisow MJ, Oatley SJ. 1978. Structure of prealbumin: Secondary, tertiary and quaternary interactions determined by fourier refinement at 1.8 angstroms. $J$ Mol Biol 121: 339-356.

Bosco DA, Fowler DM, Zhang Q, Nieva J, Powers ET, Wentworth P, Lerner RA, Kelly JW. 2006. Elevated levels of oxidized cholesterol metabolites in Lewy body disease brains accelerate $\alpha$-synuclein fibrilization. [Erratum to document cited in CA145:005691.] Nat Chem Biol 2: 346.

Brandt F, Carlson L-A, Hartl FU, Baumeister W, Gruenewald K. 2010. The three-dimensional organization of polyribosomes in intact human cells. Mol Cell 39: 560-569.

Brockmeier A, Brockmeier U, Williams DB. 2009. Distinct contributions of the lectin and arm domains of calnexin to its molecular chaperone function. J Biol Chem 284: 3433-3444.
Brodsky JL, McCracken AA. 1997. ER-associated and proteasome-mediated protein degradation: How two topologically restricted events came together. Trends Cell Biol 7: 151-156.

Chaney MO, Baudry J, Esh C, Childress J, Luehrs DC, Kokjohn TA, Roher AE. 2003. A $\beta$, aging, and Alzheimer's disease: A tale, models, and hypotheses. Neurol Res 25: 581-589.

Chang HH, Asano N, Ishii S, Ichikawa Y, Fan JQ. 2006. Hydrophilic iminosugar active-site-specific chaperones increase residual glucocerebrosidase activity in fibroblasts from Gaucher patients. FEBS J 273: 4082-4092.

Chang L, Bertelsen EB, Wisen S, Larsen EM, Zuiderweg ERP, Gestwicki JE. 2008. High-throughput screen for small molecules that modulate the ATPase activity of the molecular chaperone DnaK. Anal Biochem 372: 167-176.

Chang L, Thompson AD, Ung P, Carlson HA, Gestwicki JE. 2010. Mutagenesis reveals the complex relationships between ATPase rate and the chaperone activities of Escherichia coli heat shock protein 70 (Hsp70/DnaK). J Biol Chem 285: 21282-21291.

Chang L, Miyata Y, Ung PMU, Bertelsen EB, McQuade TJ, Carlson HA, Zuiderweg ERP, Gestwicki JE. 2011. Chemical screens against a reconstituted multiprotein complex: Myricetin blocks dnaj regulation of dnak through an allosteric mechanism. Chem Biol 18: 210-221.

Chen X, Yin XM. 2011. Coordination of autophagy and the proteasome in resolving endoplasmic reticulum stress. Vet Pathol 48: 245-253.

Choi S-W, Reixach N, Connelly S, Johnson SM, Wilson IA, Kelly JW. 2010a. A substructure combination strategy to create potent and selective transthyretin kinetic stabilizers that prevent amyloidogenesis and cytotoxicity. $J$ Am Chem Soc 132: 1359-1370.

Choi S, Connelly S, Reixach N, Wilson IA, Kelly JW. 2010b. Chemoselective small molecules that covalently modify one lysine in a non-enzyme protein in plasma. Nat Chem Biol 6: 133-139.

Cohen E, Dillin A. 2008. The insulin paradox: Aging, proteotoxicity and neurodegneration. Nat Rev Neurosci 9: 759-767.

Cohen FE, Kelly JW. 2003. Therapeutic approaches to protein-misfolding diseases. Nature 426: 905-909.

Cohen E, Bieschke J, Perciavalle RM, Kelly JW, Dillin A. 2006. Opposing activities protect against age-onset proteotoxicity. Science 313: 1604-1610.

Cohen E, Paulsson JF, Blinder P, Burstyn-Cohen T, Du D, Estepa G, Adame A, Pham HM, Holzenberger M, Kelly JW, et al. 2009. Reduced IGF-1 signaling delays age-associated proteotoxicity in mice. Cell 139: 1157-1169.

Cohen E, Du D, Joyce D, Kapernick EA, Volovik Y, Kelly JW, Dillin A. 2010. Temporal requirements of insulin/IGF-1 signaling for proteotoxicity protection. Aging Cell 9: $126-134$.

Colon W, Kelly JW. 1992. Partial denaturation of transthyretin is sufficient for amyloid fibril formation in vitro. Biochemistry 31: 8654-8660.

Compain P, Martin OR, Boucheron C, Godin G, Yu L, Ikeda K, Asano N. 2006. Design and synthesis of highly potent and selective pharmacological chaperones for the 
treatment of Gaucher's disease. Chembiochemistry 7: $1356-1359$.

Connelly S, Choi S, Johnson SM, Kelly JW, Wilson IA. 2010. Structure-based design of kinetic stabilizers that ameliorate the transthyretin amyloidoses. Curr Opin Struct Biol 20: $54-62$.

Cornwell GG 3 rd, Sletten K, Johansson B, Westermark P. 1988. Evidence that the amyloid fibril protein in senile systemic amyloidosis is derived from normal prealbumin. Biochem Biophys Res Commun 154: 648-653.

Cowen LE, Singh SD, Kohler JR, Collins C, Zaas A, Schell WA, Aziz H, Mylonakis E, Perfect JR, Whitesell L, et al. 2009. Harnessing Hsp90 function as a powerful, broadly effective therapeutic strategy for fungal infectious disease. Proc Nat Acad Sci 106: 2818-2823.

Culyba EK, Price JL, Hanson SR, Dhar A, Wong C-H, Gruebele M, Powers ET, Kelly JW. 2011. Protein native-state stabilization by placing aromatic side chains in n-glycosylated reverse turns. Science 331: 571-575.

Dai C, Whitesell L, Rogers AB, Lindquist S. 2007. Heatshock factor 1 is a powerful multifaceted modifier of carcinogenesis. Cell 130: 1005-1018.

Deechongkit S, Nguyen H, Powers ET, Dawson PE, Gruebele M, Kelly JW. 2004. Context-dependent contributions of backbone hydrogen bonding to $\beta$-sheet folding energetics. Nature 430: 101-105.

DeMartino GN, Gillette TG. 2007. Proteasomes: Machines for all reasons. Cell 129: 659-662.

Didomenico BJ, Bugaisky GE, Lindquist S. 1982. The heatshock is self-regulated at both the transcriptional and posttranslational levels. Cell 31: 593-603.

Dill KA, Chan HS. 1997. From Levinthal to pathway funnels. Nat Struct Biol 4: 10-19.

Dillin A, Crawford DK, Kenyon C. 2002. Timing Requirements for Insulin/IGF-1 Signaling in C. elegans. Science 298: $830-834$

Douglas PM, Dillin A. 2010. Protein homeostasis and aging in neurodegeneration. J Cell Biol 190: 719-729.

Douglas NR, Reissmann S, Zhang J, Chen B, Jakana J, Kumar R, Chiu W, Frydman J. 2011. Dual action of ATP hydrolysis couples lid closure to substrate release into the group ii chaperonin chamber. Cell 144: 240-252.

Drummond DA, Wilke CO. 2008. Mistranslation-induced protein misfolding as a dominant constraint on codingsequence evolution. Cell 134: 341-352.

Du D, Murray AN, Cohen E, Kim H-E, Simkovsky R, Dillin A, Kelly JW. 2011. A kinetic aggregation assay allowing selective and sensitive amyloid- $\beta$ quantification in cells and tissues. Biochemistry 50: 1607-1617.

Dvir H, Harel M, McCarthy AA, Toker L, Silman I, Futerman AH, Sussman JL. 2003. X-ray structure of human acid- $\beta$-glucosidase, the defective enzyme in Gaucher disease. EMBO Rep 4: 704-709.

Dyson HJ, Wright PE. 2005. Intrinsically unstructured proteins and their functions. Nat Rev Mol Cell Biol 6: 197-208.

Edlich F, Fischer G. 2006. Pharmacological targeting of catalyzed protein folding: The example of peptide bond cis/ trans isomerases. Handb Exp Pharmacol 172: 359-404.
Ellgaard L, Molinari M, Helenius A. 1999. Setting the standards: Quality control in the secretory pathway. Science 286: $1882-1888$.

Ellis RJ, Hartl FU. 1999. Principles of protein folding in the cellular environment. Curr Op Struct Biol 9: 102-110.

Ellis RJ, Minton AP. 2006. Protein aggregation in crowded environments. Biol Chem 387: 485-497.

Evans CG, Chang L, Gestwicki JE. 2010. Heat shock protein 70 (Hsp70) as an emerging drug target. J Med Chem 53: 4585-4602.

Fan J-Q. 2001. Potential drug therapies for lysosomal storage disorders. Frontiers Biotechnol Pharmaceuticals 2: 275-291.

Fan JQ. 2003. A contradictory treatment for lysosomal storage disorders: Inhibitors enhance mutant enzyme activity. Trends Pharmacol Sci 24: 355-360.

Fan JQ, Ishii S, Asano N, Suzuki Y. 1999. Accelerated transport and maturation of lysosomal $\alpha$-galactosidase $\mathrm{A}$ in Fabry lymphoblasts by an enzyme inhibitor. Nature Med 5: 112-115.

Fewell SW, Travers KJ, Weissman JS, Brodsky JL. 2001. The action of molecular chaperones in the early secretory pathway. Annu Rev Genet 35: 149-191.

Finley D. 2009. Recognition and processing of ubiquitinprotein conjugates by the proteasome. Annu Rev Biochem 78: $477-513$.

Fischer G, Schmid FX. 1999. Peptidyl-prolyl cis/trans isomerases, pp. 461-489. Harwood, Newark, NJ.

Foss TR, Wiseman RL, Kelly JW. 2005. The pathway by which the tetrameric protein transthyretin dissociates. Biochemistry 44: 15525-15533.

Frustaci A, Chimenti C, Ricci R, Natale L, Russo MA, Pieroni M, Eng CM, Desnick RJ. 2001. Brief report: Improvement in cardiac function in the cardiac variant of Fabry's disease with galactose-infusion therapy. New Eng J Med 345: $25-32$.

Futerman AH, van Meer G. 2004. The cell biology of lysosomal storage disorders. Nat Rev Mol Cell Biol 5: 554-565.

Geller R, Vignuzzi M, Andino R, Frydman J. 2007. Evolutionary constraints on chaperone-mediated folding provide an antiviral approach refractory to development of drug resistance. Genes Dev 21: 195-205.

Genereux JC, Wiseman RL. 2011. Chemically targeting the emergent properties of a chaperone complex. Chem Biol 18: 144-145.

Ghosh R, Lipson KL, Sargent KE, Mercurio AM, Hunt JS, Ron D, Urano F. 2010. Transcriptional regulation of VEGF-A by the unfolded protein response pathway. PLoS One 5: e9575.

Gidalevitz T, Ben-Zvi A, Ho KH, Brignull HR, Morimoto RI. 2006. Progressive disruption of cellular protein folding in models of polyglutamine diseases. Science 311: $1471-1474$.

Glasser SP. 2006. Antihypertensive safety and efficacy and physician and patient satisfaction: Results from a phase 4 practice-based clinical experience trial with diltiazem LA. Adv Ther 23: 284-294.

Green NS, Palaninathan SK, Sacchettini JC, Kelly JW. 2003. Synthesis and characterization of potent bivalent amyloidosis inhibitors that bind prior to transthyretin tetramerization. J Am Chem Soc 125: 13404-13414. 
Green NS, Foss TR, Kelly JW. 2005. Genistein, a natural product from soy, is a potent inhibitor of transthyretin amyloidosis. Proc Natl Acad Sci 102: 14545-14550.

Gusella JF, MacDonald ME. 2009. Huntington's disease: The case for genetic modifiers. Genome Med 1: 80

Hammarstrom P, Jiang X, Hurshman AR, Powers ET, Kelly JW. 2002. Sequence-dependent denaturation energetics: A major determinant in amyloid disease diversity. Proc Natl Acad Sci 99: 16427-16432.

Hammarstrom P, Wiseman RL, Powers ET, Kelly JW. 2003. Prevention of transthyretin amyloid disease by changing protein misfolding energetics. Science 299: 713-716.

Harding HP, Zhang Y, Zeng H, Novoa I, Lu PD, Calfon M, Sadri N, Yun C, Popko B, Paules R, et al. 2003. An integrated stress response regulates amino acid metabolism and resistance to oxidative stress. Mol Cell 11: 619-633.

Hartl FU, Hayer-Hartl M. 2009. Converging concepts of protein folding in vitro and in vivo. Nat Struct Mol Biol 16: $574-581$.

Haslbeck M, Franzmann T, Weinfurtner D, Buchner J. 2005. Some like it hot: The structure and function of small heat-shock proteins. Nature Struct Mol Biol 12: 842-846.

Hidvegi T, Ewing M, Hale P, Dippold C, Beckett C, Kemp C, Maurice N, Mukherjee A, Goldbach C, Watkins S, et al. 2010. An autophagy-enhancing drug promotes degradation of mutant $\alpha 1$-antitrypsin $\mathrm{z}$ and reduces hepatic fibrosis. Science 329: 229-232.

Hsu A, Murphy CT, Kenyon C. 2003. Regulation of aging and age-related disease by DAF- 16 and heat-shock factor. Science 300: 1142-1145.

Hurshman AR, White JT, Powers ET, Kelly JW. 2004. Transthyretin aggregation under partially denaturing conditions is a downhill polymerization. Biochemistry 43: 7365-7381.

Hurshman Babbes AR, Powers ET, Kelly JW. 2008. Quantification of the thermodynamically linked quaternary and tertiary structural stabilities of transthyretin and its disease-associated variants: The relationship between stability and amyloidosis. Biochemistry 47: 6969-6984.

Hutt DM, Herman D, Rodrigues APC, Noel S, Pilewski JM, Matteson J, Hoch B, Kellner W, Kelly JW, Schmidt A, et al. 2010. Reduced histone deacetylase 7 activity restores function to misfolded CFTR in cystic fibrosis. Nature Chem Biol 6: 25-33.

Ishii S, Kase R, Sakuraba H, Suzuki Y. 1993. Characterization of a mutant $\alpha$-galactosidase gene-product for the late-onset cardiac form of Fabry disease. Biochem Biophys Res Commun 197: 1585-1589.

Jacobson DR, Pastore RD, Yaghoubian R, Kane I, Gallo G, Buck FS, Buxbaum JN. 1997. Variant-sequence transthyretin (isoleucine 122) in late-onset cardiac amyloidosis in black Americans. N Engl J Med 336: 466-473.

Jager M, Nguyen H, Crane JC, Kelly JW, Gruebele M. 2001. The folding mechanism of a $\alpha$-sheet: The WW domain J Mol Biol 311: 373-393.

Jager M, Deechongkit S, Koepf EK, Nguyen H, Gao J, Powers ET, Gruebele M, Kelly JW. 2008. 2008 Vincent du Vigneaud award lecture. Understanding the mechanism of $\alpha$-sheet folding from a chemical and biological perspective. Biopolymers 90: 751-758.
Jahn TR, Radford SE. 2008. Folding versus aggregation: Polypeptide conformations on competing pathways. Arch Biochem Biophys 469: 100-117.

Jankowsky JL, Slunt HH, Ratovitski T, Jenkins NA, Copeland NG, Borchelt DR. 2001. Coexpression of multiple transgenes in mouse CNS: A comparison of strategies. Biomol Eng 17: 157-165.

Jarosz DF, Taipale M, Lindquist S. 2010. Protein homeostasis and the phenotypic manifestation of genetic diversity: Principles and mechanisms. Annu Rev Genet 44: 189216.

Jiang X, Buxbaum JN, Kelly JW. 2001a. The V122I cardiomyopathy variant of transthyretin increases the velocity of rate-limiting tetramer dissociation, resulting in accelerated amyloidosis. Proc Natl Acad Sci 98: 14943-14948.

Jiang X, Smith CS, Petrassi HM, Hammarstrom P, White JT, Sacchettini JC, Kelly JW. 2001b. An engineered transthyretin monomer that is nonamyloidogenic, unless it is partially denatured. Biochemistry 40: 11442-11452.

Jinwal UK, Miyata Y, Koren J III, Jones JR, Trotter JH, Chang L, O'Leary J, Morgan D, Lee DC, Shults CL, et al. 2009. Chemical manipulation of Hsp70 ATPase activity regulates Tau stability. J Neurosci 29: 12079-12088.

Johnson AE. 2009. The structural and functional coupling of two molecular machines, the ribosome and the translocon. J Cell Biol 185: 765-767.

Johnson SM, Petrassi HM, Palaninathan SK, Mohamedmohaideen NN, Purkey HE, Nichols C, Chiang KP, Walkup T, Sacchettini JC, Sharpless KB, et al. 2005a. Bisaryloxime ethers as potent inhibitors of transthyretin amyloid fibril formation. J Med Chem 48: 1576-1587.

Johnson SM, Wiseman RL, Sekijima Y, Green NS, AdamskiWerner SL, Kelly JW. 2005b. Native state kinetic stabilization as a strategy to ameliorate protein misfolding diseases: A focus on the transthyretin amyloidoses. Acc Chem Res 38: 911-921.

Johnson SM, Connelly S, Wilson IA, Kelly JW. 2008a. Bbiochemical and structural evaluation of highly selective 2arylbenzoxazole-based transthyretin amyloidogenesis inhibitors. J Med Chem 51: 260-270.

Johnson SM, Connelly S, Wilson IA, Kelly JW. 2008b. Toward optimization of the linker substructure common to transthyretin amyloidogenesis inhibitors using biochemical and structural studies. J Med Chem 51: 6348 6358.

Johnson SM, Connelly S, Wilson IA, Kelly JW. 2009. Toward optimization of the second aryl substructure common to transthyretin amyloidogenesis inhibitors using biochemical and structural studies. J Med Chem 52: 1115-1125.

Johnson SM, Wiseman RL, Reixach N, Paulsson JF, Choi S, Powers ET, Buxbaum JN, Kelly JW. 2010. Understanding and ameliorating the TTR amyloidoses, pp. 967-1003. John Wiley \& Sons, Hoboken, NJ.

Junker M, Besingi RN, Clark PL. 2009. Vectorial transport and folding of an autotransporter virulence protein during outer membrane secretion. Mol Microbiol 71: $1323-1332$.

Kampinga HH, Craig EA. 2010. The HSP70 chaperone machinery: J proteins as drivers of functional specificity. Nat Rev Mol Cell Biol 11: 579-592. 
Kauzmann W. 1959. Some factors in the interpretation of protein denaturation. In Advances in protein chemistry (ed. CB Anfinsen, et al.), Vol. 14, pp. 1-63. Academic Press, New York.

Kenyon C. 2005. The plasticity of aging: Insights from longlived mutants. Cell 120: 449-460.

Kirstein-Miles J, Morimoto RI. 2010a. Caenorhabditis elegans as a model system to study intercompartmental proteostasis: Interrelation of mitochondrial function, longevity, and neurodegenerative diseases. Dev Dyn 239: $1529-1538$.

Kirstein-Miles J, Morimoto RI. 2010b. Peptides signal mitochondrial stress. Cell Metab 11: 177-178.

Kitamura A, Kubota H, Pack C-G, Matsumoto G, Hirayama S, Takahashi Y, Kimura H, Kinjo M, Morimoto RI, Nagata K. 2006. Cytosolic chaperonin prevents polyglutamine toxicity with altering the aggregation state. Nature Cell Biol 8: 1163-1169.

Klabunde T, Petrassi HM, Oza VB, Raman P, Kelly JW, Sacchettini JC. 2000. Rational design of potent human transthyretin amyloid disease inhibitors. Nat Struct Biol 7: 312-321.

Kon M, Cuervo AM. 2010. Autophagy: An alternative degradation mechanism for misfolded proteins, pp. 113-129. John Wiley \& Sons, Hoboken, NJ.

Koonin EV. 2010. The origin and early evolution of eukaryotes in the light of phylogenomics. GenomeBiology 11: 209.

Koren J III, Jinwal UK, Jin Y, O’Leary J, Jones JR, Johnson AG, Blair LJ, Abisambra JF, Chang L, Miyata Y, et al. 2010. Facilitating Akt clearance via manipulation of Hsp70 activity and levels. J Biol Chem 285: 2498-2505.

Korkotian E, Schwarz A, Pelled D, Schwarzmann G, Segal M, Futerman AH. 1999. Elevation of intracellular glucosylceramide levels results in an increase in endoplasmic reticulum density and in functional calcium stores in cultured neurons. J Biol Chem 274: 21673-21678.

Koulov AV, La PP, Lu B, Razvi A, Coppinger J, Dong M-Q, Matteson J, Laister R, Arrowsmith C, Yates JR III, et al. 2010. Biological and structural basis for Aha1 regulation of Hsp90 ATPase activity in maintaining proteostasis in the human disease cystic fibrosis. Mol Biol Cell 21: 871-884.

Kruse KB, Brodsky JL, McCracken AA. 2006. Autophagy. An ER protein quality control process. Autophagy 2: 135-137.

Kuntz ID Jr, Kauzmann W. 1974. Hydration of proteins and polypeptides. Adv Protein Chem 28: 239-345.

Lai Z, Colon W, Kelly JW. 1996. The acid-mediated denaturation pathway of transthyretin yields a conformational intermediate which can self-assemble into amyloid. Biochemistry 35: 6470-6482.

Lamark T, Johansen T. 2010. Autophagy: Links with the proteasome. Curr Opin Cell Biol 22: 192-198.

Lambert MP, Barlow AK, Chromy BA, Edwards C, Freed R, Liosatos M, Morgan TE, Rozovsky I, Trommer B, Viola $\mathrm{KL}$, et al. 1998. Diffusible, nonfibrillar ligands derived from $\mathrm{A} \beta 1-42$ are potent central nervous system neurotoxins. Proc Natl Acad Sci 95: 6448-6453.
Larkin A, Imperiali B. 2011. The expanding horizons of asparagine-linked glycosylation. Biochemistry 50: 4411-4426.

Lashuel HA, Hartley D, Petre BM, Walz T, Lansbury PT. 2002. Neurodegenerative disease: Amyloid pores from pathogenic mutations. Nature 418: 291.

Lecker SH, Goldberg AL, Mitch WE. 2006. Protein degradation by the ubiquitin-proteasome pathway in normal and disease states. J Am Soc Nephrol 17: 1807-1819.

Lee B-H, Lee MJ, Park S, Oh D-C, Elsasser S, Chen P-C, Gartner C, Dimova N, Hanna J, Gygi SP, et al. 2010. Enhancement of proteasome activity by a small-molecule inhibitor of USP14. Nature 467: 179-184.

Li H, Korennykh AV, Behrman SL, Walter P. 2010. Mammalian endoplasmic reticulum stress sensor IRE1 signals by dynamic clustering. Proc Natl Acad Sci 107: 16113-16118, S16113/16111-S16113/16115.

Li J, Richter K, Buchner J. 2011. Mixed Hsp90-cochaperone complexes are important for the progression of the reaction cycle. Nat Struct Mol Biol 18: 61-66.

Lieberman RL, Wustman BA, Huertas P, Powe AC, Pine CW, Khanna R, Schlossmacher MG, Ringe D, Petsko GA. 2007. Structure of acid $\beta$-glucosidase with pharmacological chaperone provides insight into Gaucher disease. Nature Chem Biol 3: 101-107.

Lin H, Sugimoto Y, Ohsaki Y, Ninomiya H, Oka A, Taniguchi M, Ida H, Eto Y, Ogawa S, Matsuzaki Y, et al. 2004. $\mathrm{N}$-Octyl- $[\beta]$-valienamine up-regulates activity of F213I mutant $[\beta]$-glucosidase in cultured cells: A potential chemical chaperone therapy for Gaucher disease. Biochim Biophys Acta (BBA) - Molecular Basis of Disease 1689: 219-228.

Liu K, Cho HS, Lashuel HA, Kelly JW, Wemmer DE. 2000. A glimpse of a possible amyloidogenic intermediate of transthyretin. Nat Struct Biol 7: 754-757.

Liu XL, Done SC, Yan K, Kilpelaeinen P, Pikkarainen T, Tryggvason K. 2004. Defective trafficking of nephrin missense mutants rescued by a chemical chaperone. J Am Soc Nephrol 15: 1731-1738.

Lloyd-Evans E, Pelled D, Riebeling C, Bodennec J, de-Morgan A, Waller H, Schiffmann R, Futerman AH. 2003. Glucosylceramide and glucosylsphingosine modulate calcium mobilization from brain microsomes via different mechanisms. J BiolChem 278: 23594-23599.

Lomas DA, Perlmutter DH. 2010. $\alpha$-1-antitrypsin deficiency, pp. 403-423, 401 plate. John Wiley \& Sons, Hoboken, NJ.

Maier T, Ferbitz L, Deuerling E, Ban N. 2005. A cradle for new proteins: Trigger factor at the ribosome. Curr Opin Struct Biol 15: 204-212.

Marciniak SJ, Ron D. 2006. Endoplasmic reticulum stress signaling in disease. Physiol Rev 86: 1133-1149.

McCracken AA, Brodsky JL. 2003. Evolving questions and paradigm shifts in endoplasmic-reticulum-associated degradation (ERAD). BioEssays 25: 868-877.

McCracken AA, Werner ED, Brodsky JL. 1998. Endoplasmic reticulum-associated protein degradation: An unconventional route to a familiar fate. Adv Mol Cell Biol 27: $165-200$.

McCutchen SL, Lai Z, Miroy G, Kelly JW, Colon W. 1995. Comparison of lethal and non-lethal transthyretin 
S.L. Lindquist and J.W. Kelly

variants and their relationship to amyloid disease. Biochemistry 34: 13527-13536.

McDonald E, Workman P, Jones K. 2006. Inhibitors of the HSP90 molecular chaperone: Attacking the master regulator in cancer. Curr Top Med Chem 6: 1091-1107.

Merz F, Boehringer D, Schaffitzel C, Preissler S, Hoffmann A, Maier T, Rutkowska A, Lozza J, Ban N, Bukau B, et al. 2008. Molecular mechanism and structure of trigger factor bound to the translating ribosome. EMBO J 27: $1622-1632$.

Miller SR, Sekijima Y, Kelly JW. 2004. Native state stabilization by NSAIDs inhibits transthyretin amyloidogenesis from the most common familial disease variants. Lab Invest 84: 545-552.

Miroy GJ, Lai Z, Lashuel HA, Peterson SA, Strang C, Kelly JW. 1996. Inhibiting transthyretin amyloid fibril formation via protein stabilization. Proc Natl Acad Sci 93: 15051-15056.

Miyata Y, Chang L, Bainor A, McQuade TJ, Walczak CP, Zhang Y, Larsen MJ, Kirchhoff P, Gestwicki JE. 2010. High-throughput screen for Escherichia coli heat shock protein 70 (Hsp70/DnaK): ATPase assay in low volume by exploiting energy transfer. J Biomol Screening 15: $1211-1219$.

Morimoto RI. 1998. Regulation of the heat shock transcriptional response: Cross talk between a family of heat shock factors, molecular chaperones, and negative regulators. Genes Dev 12: 3788-3796.

Morimoto RI, Cuervo AM. 2009. Protein homeostasis and aging: Taking care of proteins from the cradle to the grave. J Gerontol, Ser A 64A: 167-170.

Morley JF, Morimoto RI. 2004. Regulation of longevity in Caenorhabditis elegans by heat shock factor and molecular chaperones. Mol Biol Cell 15: 657-664.

Morley JF, Brignull HR, Weyers JJ, Morimoto RI. 2002. The threshold for polyglutamine-expansion protein aggregation and cellular toxicity is dynamic and influenced by aging in Caenorhabditis elegans. Proc Natl Acad Sci 99: 10417-10422.

Mu T-W, Fowler DM, Kelly JW. 2008a. Partial restoration of mutant enzyme homeostasis in three distinct lysosomal storage disease cell lines by altering calcium homeostasis. PLoS Biol 6: 253-265.

Mu T-W, Ong DST, Wang Y-J, Balch WE, Yates JR 3rd, Segatori L, Kelly JW. 2008b. Chemical and biological approaches synergize to ameliorate protein-folding diseases. Cell 134: 769-781.

Mulder AM, Yoshioka C, Beck AH, Bunner AE, Milligan RA, Potter CS, Carragher B, Williamson JR. 2010. Visualizing ribosome biogenesis: Parallel assembly pathways for the 30S subunit. Science 330: 673-677.

Namba Y, Tomonaga M, Ohtsuka K, Oda M, Ikeda K. 1991. HSP 70 is associated with abnormal cytoplasmic inclusions characteristic of neurodegenerative diseases. Brain Nerve 43: 57-60.

Oliveberg M, Wolynes PG. 2005. The experimental survey of protein-folding energy landscapes. Q Rev Biophys 38: 245-288.

Olzscha H, Schermann SM, Woerner AC, Pinkert S, Hecht MH, Tartaglia GG, Vendruscolo M, Hayer-Hartl M, Hartl FU, Vabulas RM. 2011. Amyloid-like aggregates sequester numerous metastable proteins with essential cellular functions. Cell 144: 67-78.

Ong DST, Mu T-W, Palmer AE, Kelly JW. 2010. Endoplasmic reticulum $\mathrm{Ca}^{2+}$ increases enhance mutant glucocerebrosidase proteostasis. Nat Chem Biol 6: 424-432.

Onuchic JN, Wolynes PG. 2004. Theory of protein folding. Curr Opin Struct Biol 14: 70-75.

Orlowski RZ, Kuhn DJ. 2008. Proteasome inhibitors in cancer therapy: Lessons from the first decade. Clin Cancer Res 14: 1649-1657.

Oza VB, Petrassi HM, Purkey HE, Kelly JW. 1999. Synthesis and evaluation of anthranilic acid-based transthyretin amyloid fibril inhibitors. Bioorg Med Chem Lett 9: 1-6.

Oza VB, Smith C, Raman P, Koepf EK, Lashuel HA, Petrassi HM, Chiang KP, Powers ET, Sachettinni J, Kelly JW. 2002. Synthesis, structure, and activity of diclofenac analogues as transthyretin amyloid fibril formation inhibitors. J Med Chem 45: 321-332.

Ozcan U, Yilmaz E, Ozcan L, Furuhashi M, Vaillancourt E, Smith Ross O, Gorgun Cem Z, Hotamisligil GS. 2006. Chemical chaperones reduce ER stress and restore glucose homeostasis in a mouse model of type 2 diabetes. Science 313: 1137-1140.

Pelled D, Trajkovic-Bodennec S, Lloyd-Evans E, Sidransky E, Schiffmann R, Futerman AH. 2005. Enhanced calcium release in the acute neuronopathic form of Gaucher disease. Neurobiol Dis 18: 83-88.

Perlmutter DH. 2011. $\alpha$-1-antitrypsin deficiency: importance of proteasomal and autophagic degradative pathways in disposal of liver disease-associated protein aggregates. Annu Rev Med 62: 333-345.

Petrassi HM, Klabunde T, Sacchettini J, Kelly JW. 2000. Structure-based design of N-phenyl phenoxazine transthyretin amyloid fibril inhibitors. J Am Chem Soc 122: 2178-2192.

Petrassi HM, Johnson SM, Purkey HE, Chiang KP, Walkup T, Jiang X, Powers ET, Kelly JW. 2005. Potent and selective structure-based dibenzofuran inhibitors of transthyretin amyloidogenesis: Kinetic stabilization of the native state. J Am Chem Soc 127: 6662-6671.

Powers ET, Balch WE. 2008. Costly mistakes: Translational infidelity and protein homeostasis. Cell 134: 204-206.

Powers ET, Morimoto RI, Dillin A, Kelly JW, Balch WE. 2009. Biological and chemical approaches to diseases of proteostasis deficiency. Annu Rev Biochem 78: 23.2123.33.

Prahlad V, Cornelius T, Morimoto RI. 2008. Regulation of the cellular heat shock response in Caenorhabditis elegans by thermosensory neurons. Science 320: 811-814.

Purkey HE, Dorrell MI, Kelly JW. 2001. Evaluating the binding selectivity of transthyretin amyloid fibril inhibitors in blood plasma. Proc Natl Acad Sci 98: 5566-5571.

Purkey HE, Palaninathan SK, Kent KC, Smith C, Safe SH, Sacchettini JC, Kelly JW. 2004. Hydroxylated polychlorinated biphenyls selectively bind transthyretin in blood and inhibit amyloidogenesis: Rationalizing rodent $\mathrm{PCB}$ toxicity. Chem Biol 11: 1719-1728.

Qu BH, Strickland EH, Thomas PJ. 1997. Localization and suppression of a kinetic defect in cystic fibrosis transmembrane conductance regulator folding. J Biol Chem 272: $15739-15744$. 
Razavi H, Palaninathan SK, Powers ET, Wiseman RL, Purkey HE, Mohamedmohaideen NN, Deechongkit S, Chiang KP, Dendle MTA, Sacchettini JC, et al. 2003. Benzoxazoles as transthyretin amyloid fibril inhibitors: Synthesis, evaluation, and mechanism of action. Angewandte Chemie, International Edition 42: 2758-2761.

Razavi H, Powers ET, Purkey HE, Adamski-Werner SL, Chiang KP, Dendle MTA, Kelly JW. 2005. Design, synthesis, and evaluation of oxazole transthyretin amyloidogenesis inhibitors. Bioorg Med Chem Lett 15: 1075-1078.

Richardson PG. 2004. A review of the proteasome inhibitor bortezomib in multiple myeloma. Expert Opin Pharmacother 5: 1321-1331.

Richardson PG, Mitsiades C. 2005. Bortezomib: Proteasome inhibition as an effective anticancer therapy. Future Oncol 1: 161-171.

Richter K, Buchner J. 2011. Closing in on the Hsp90 chaperone-client relationship. Structure 19: 445-446.

Rieger TR, Morimoto RI, Hatzimanikatis V. 2005. Mathematical modeling of the eukaryotic heat-shock response: Dynamics of the hsp70 promoter. Biophys J 88: 16461658.

Riordan JR. 1999. Cystic fibrosis as a disease of misprocessing of the cystic fibrosis transmembrane conductance regulator glycoprotein. Am J Hum Genet 64: 1499-1504.

Riordan JR. 2008. CFTR function and prospects for therapy. Annu Rev Biochem 77: 701-726.

Ron D, Walter P. 2007. Signal integration in the endoplasmic reticulum unfolded protein response. Nature Rev Mol Cell Biol 8: 519-529.

Sawkar AR, Cheng W-C, Beutler E, Wong C-H, Balch WE, Kelly JW. 2002. Chemical chaperones increase the cellular activity of N370S b-glucosidase: A therapeutic strategy for Gaucher disease. Proc Natl Acad Sci 99: 15428-15433.

Sawkar AR, Adamski-Werner SL, Cheng W-C, Wong C-H, Beutler E, Zimmer K-P, Kelly JW. 2005. Gaucher disease-associated glucocerebrosidases show mutationdependent chemical chaperoning profiles. Chem Biol 12: $1235-1244$.

Sawkar AR, D'Haeze W, Kelly JW. 2006a. Therapeutic strategies to ameliorate lysosomal storage disorders-a focus on Gaucher disease. Cell Mol Life Sci 63: 1179-1192.

Sawkar AR, Schmitz M, Zimmer K-P, Reczek D, Edmunds T, Balch WE, Kelly JW. 2006b. Chemical chaperones and permissive temperatures alter the cellular localization of Gaucher disease associated glucocerebrosidase variants. ACS Chem Biol 1: 235-251.

Schroder M, Kaufman RJ. 2005. The mammalian unfolded protein response. Ann Rev Biochem 74: 739-789.

Schue A. 2009. The mitochondrial hypothesis of age. LaborPraxis 33: 36-37.

Sekijima Y, Wiseman RL, Matteson J, Hammarstrom P, Miller SR, Sawkar AR, Balch WE, Kelly JW. 2005. The biological and chemical basis for tissue-selective amyloid disease. Cell 121: 73-85.

Sekijima Y, Dendle MA, Kelly JW. 2006. Orally administered diflunisal stabilizes transthyretin against dissociation required for amyloidogenesis. Amyloid 13: 236-249.

Selkoe DJ. 2004. Cell biology of protein misfolding: The examples of Alzheimer's and Parkinson's diseases. Nat Cell Biol 6: 1054-1061.
Selkoe DJ. 2008. Soluble oligomers of the amyloid $\beta$-protein impair synaptic plasticity and behavior. Behav Brain Res 192: $106-113$.

Shan S-o, Walter P. 2005. Cotranslational protein targeting by the signal recognition particle. FEBS Lett 579: 921-926.

Shang J, Gao N, Kaufman RJ, Ron D, Harding HP, Lehrman MA. 2007. Translation attenuation by PERK balances ER glycoprotein synthesis with lipid-linked oligosaccharide flux. J Cell Biol 176: 605-616.

Singer MA, Lindquist S. 1998. Multiple effects of trehalose on protein folding in vitro and in vivo. Mol Cell 1: 639-648.

Smaili S, Hirata H, Ureshino R, Monteforte PT, Morales AP, Muler ML, Terashima J, Oseki K, Rosenstock TR, Lopes GS, et al. 2009. Calcium and cell death signaling in neurodegeneration and aging. Ann Acad Bras Cienc 81: 467-475.

Smith DM, Fraga H, Reis C, Kafri G, Goldberg AL. 2011. ATP binds to proteasomal ATPases in pairs with distinct functional effects, implying an ordered reaction cycle. Cell 144: 526-538.

Steet RA, Chung S, Wustman B, Powe A, Do H, Kornfeld SA. 2006. The iminosugar isofagomine increases the activity of N370S mutant acid $\beta$-glucosidase in Gaucher fibroblasts by several mechanisms. PNAS 103: 13813-13818.

Taipale M, Jarosz DF, Lindquist S. 2010. HSP90 at the hub of protein homeostasis: Emerging mechanistic insights. Nat Rev Mol Cell Biol 11: 515-528.

Tam S, Geller R, Spiess C, Frydman J. 2006. The chaperonin TRiC controls polyglutamine aggregation and toxicity through subunit-specific interactions. Nature Cell Biol 8: $1155-1162$.

Tang Y-C, Chang H-C, Hayer-Hartl M, Hartl FU. 2007. Snapshot: Molecular chaperones, part II. Cell 128: 412.

Tang Y-C, Chang H-C, Chakraborty K, Hartl FU, HayerHartl M. 2008. Essential role of the chaperonin folding compartment in vivo. EMBO J 27: 1458-1468.

Tanzi RE, Bertram L. 2005. Twenty years of the Alzheimer's disease amyloid hypothesis: A genetic perspective. Cell 120: $545-555$.

Tatsuta T, Langer T. 2008. Quality control of mitochondria: Protection against neurodegeneration and ageing. EMBO J 27: 306-314

Tojo K, Sekijima Y, Kelly JW, Ikeda S-i. 2006. Diflunisal stabilizes familial amyloid polyneuropathy-associated transthyretin variant tetramers in serum against dissociation required for amyloidogenesis. Neurosci Res 56: 441-449.

Trepel J, Mollapour M, Giaccone G, Neckers L. 2010. Targeting the dynamic HSP90 complex in cancer. Nat Rev Cancer 10: 537-549.

Tsaytler P, Harding HP, Ron D, Bertolotti A. 2011. Selective inhibition of a regulatory subunit of protein phosphatase 1 restores proteostasis. Science 332: 91-94.

Vidal M, Cusick ME, Barabasi A-L. 2011. Interactome networks and human disease. Cell 144: 986-998.

Voellmy R, Boellmann F. 2007. Chaperone regulation of the heat shock protein response. Adv Exp Med Biol 594: 89-99. 
S.L. Lindquist and J.W. Kelly

Voisine C, Pedersen JS, Morimoto RI. 2010. Chaperone networks: Tipping the balance in protein folding diseases. Neurobiol Dis 40: 12-20.

Volchuk A, Ron D. 2010. The endoplasmic reticulum stress response in the pancreatic $\beta$-cell. Diabetes, Obes Metab 12: $48-57$.

Walsh DM, Klyubin I, Fadeeva JV, Cullen WK, Anwyl R, Wolfe MS, Rowan MJ, Selkoe DJ. 2002. Naturally secreted oligomers of amyloid b protein potently inhibit hippocampal long-term potentiation in vivo. Nature 416: 535-539.

Wang X, Venable J, LaPointe P, Hutt DM, Koulov AV, Coppinger J, Gurkan C, Kellner W, Matteson J, Plutner H, et al. 2006. Hsp90 cochaperone Ahal downregulation rescues misfolding of CFTR in cystic fibrosis. Cell 127: 803-815.

Weissman L, de S-PNC, Stevnsner T, Bohr VA. 2007. DNA repair, mitochondria, and neurodegeneration. Neuroscience 145: 1318-1329.

Wek RC, Jiang HY, Anthony TG. 2006. Coping with stress: eIF2 kinases and translational control. Biochem Soc Trans 34: 7-11.

Werner ED, Brodsky JL, McCracken AA. 1996. Proteasomedependent endoplasmic reticulum-associated protein degradation: An unconventional route to a familiar fate. Proc Natl Acad Sci 93: 13797-13801.

Westerheide SD, Bosman JD, Mbadugha BNA, Kawahara TLA, Matsumoto G, Kim S, Gu W, Devlin JP, Silverman RB, Morimoto RI. 2004. Celastrols as inducers of the heat shock response and cytoprotection. J Biol Chem 279: 56053-56060.

Westerheide SD, Morimoto RI. 2005. Heat shock response modulators as therapeutic tools for diseases of protein conformation. J Biol Chem 280: 33097-33100.

Westerheide SD, Anckar J, Stevens SM Jr, Sistonen L, Morimoto RI. 2009. Stress-inducible regulation of heat shock factor 1 by the deacetylase SIRT1. Science 323: 10631066.

Westermark P, Sletten K, Johansson B, Cornwell GG. 1990. Fibril in senile Systemic amyloidosis is derived from normal transthyretin. Proc Natl Acad Sci 87: 2843-2845.

Whitesell L, Lindquist SL. 2005. HSP90 and the chaperoning of cancer. Nat Rev Cancer 5: 761-772.

Whitesell L, Lindquist S. 2009. Inhibiting the transcription factor HSF1 as an anticancer strategy. Expert Opin Ther Targets 13: 469-478.

Williams DB. 2006. Beyond lectins: The calnexin/calreticulin chaperone system of the endoplasmic reticulum. J Cell Sci 119: 615-623.

Wiseman RL, Kelly JW. 2011. Cell biology. Phosphatase inhibition delays translational recovery. Science 332: $44-45$.
Wiseman RL, Johnson SM, Kelker MS, Foss T, Wilson IA, Kelly JW. 2005. Kinetic stabilization of an oligomeric protein by a single ligand binding event. J Am Chem Soc 127: 5540-5551.

Wiseman RL, Haynes CM, Ron D. 2010. SnapShot: The unfolded protein response. Cell 140: 590-590. e592.

Wisen S, Bertelsen EB, Thompson AD, Patury S, Ung P, Chang L, Evans CG, Walter GM, Wipf P, Carlson HA, et al. 2010. Binding of a small molecule at a protein-protein interface regulates the chaperone activity of Hsp70-Hsp40. ACS Chem Biol 5: 611-622.

Wong E, Cuervo AM. 2010. Autophagy gone awry in neurodegenerative diseases. Nat Neurosci 13: 805-811.

Yamashita T, Asl KH, Yazaki M, Benson MD. 2005. A prospective evaluation of the transthyretin Ile122 allele frequency in an African-American population. Amyloid 12: $127-130$.

Yoshida Y. 2003. Quality control of proteins in secretory pathway by N-glycans. Kagaku Kogyo 54: 771-776.

Yost HJ, Petersen RB, Linquist S. 1990. RNA metabolism: Strategies for regulation in the heat shock response. Trends Genet 6: 223-227.

Young JC, Agashe VR, Siegers K, Hartl FU. 2004. Pathways of chaperone-mediated protein folding in the cytosol. Nature Rev Mol Cell Biol 5: 781-791.

Yu L, Ikeda K, Kato A, Adachi I, Godin G, Compain P, Martin O, Asano N. 2006. $\alpha$-1-C-octyl-1-deoxynojirimycin as a pharmacological chaperone for Gaucher disease. Bioorganic Medicinal Chem 14: 7736-7744.

Yu Z, Sawkar AR, Kelly JW. 2007a. Pharmacologic chaperoning as a strategy to treat Gaucher disease. FEBS J 274: 4944-4950.

Yu ZQ, Sawkar AR, Whalen LJ, Wong CH, Kelly JW. 2007b. Isofagomine- and 2,5-anhydro-2,5-imino-D-glucitol-based glucocerebrosidase pharmacological chaperones for Gaucher disease intervention. J Medicinal Chem 50: 94-100.

Zhang Q, Powers ET, Nieva J, Huff ME, Dendle MA, Bieschke J, Glabe CG, Eschenmoser A, Wentworth P Jr, Lerner RA, et al. 2004. Metabolite-initiated protein misfolding may trigger Alzheimer's disease. Proc Natl Acad Sci 101: 4752-4757.

Zhang J, Baker ML, Schroeder GF, Douglas NR, Reissmann S, Jakana J, Dougherty M, Fu CJ, Levitt M, Ludtke SJ, et al. 2010. Mechanism of folding chamber closure in a group II chaperonin. Nature 463: 379-383.

Zhao H, Grabowski GA. 2002. Gaucher disease: Perspectives on a prototype lysosomal disease. Cell Molec Life Sci 59: 694-707.

Zhu K, Dunner K, McConkey DJ. 2010. Proteasome inhibitors activate autophagy as a cytoprotective response in human prostate cancer cells. Oncogene 29: 451-462. 


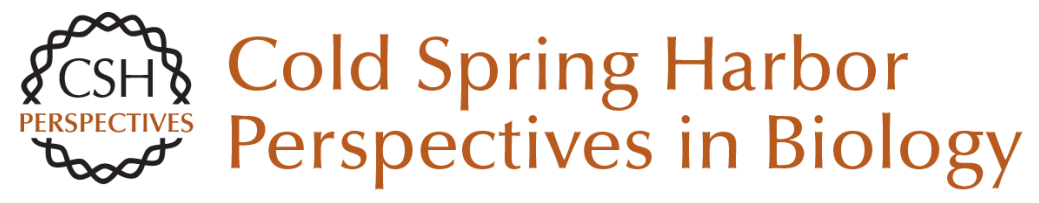

\title{
Chemical and Biological Approaches for Adapting Proteostasis to Ameliorate Protein Misfolding and Aggregation Diseases-Progress and Prognosis
}

\author{
Susan L. Lindquist and Jeffery W. Kelly \\ Cold Spring Harb Perspect Biol 2011; doi: 10.1101/cshperspect.a004507 originally published online \\ September 7, 2011
}

\section{Subject Collection Protein Homeostasis}

Proteome-Scale Mapping of Perturbed

Proteostasis in Living Cells

Isabel Lam, Erinc Hallacli and Vikram Khurana

Pharmacologic Approaches for Adapting

Proteostasis in the Secretory Pathway to

Ameliorate Protein Conformational Diseases Jeffery W. Kelly

Cell-Nonautonomous Regulation of Proteostasis

in Aging and Disease

Richard I. Morimoto

The Autophagy Lysosomal Pathway and

Neurodegeneration Steven Finkbeiner

Functional Modules of the Proteostasis Network Gopal G. Jayaraj, Mark S. Hipp and F. Ulrich Hartl

Protein Solubility Predictions Using the CamSol

Method in the Study of Protein Homeostasis Pietro Sormanni and Michele Vendruscolo

Recognition and Degradation of Mislocalized Proteins in Health and Disease

Ramanujan S. Hegde and Eszter Zavodszky
The Amyloid Phenomenon and Its Significance in Biology and Medicine

Christopher M. Dobson, Tuomas P.J. Knowles and Michele Vendruscolo

A Chemical Biology Approach to the Chaperome in Cancer--HSP90 and Beyond Tony Taldone, Tai Wang, Anna Rodina, et al.

Proteostasis in Viral Infection: Unfolding the Complex Virus-Chaperone Interplay Ranen Aviner and Judith Frydman

The Proteasome and Its Network: Engineering for Adaptability Daniel Finley and Miguel A. Prado

Functional Amyloids Daniel Otzen and Roland Riek

Chaperone Interactions at the Ribosome Elke Deuerling, Martin Gamerdinger and Stefan G. Kreft

Mechanisms of Small Heat Shock Proteins Maria K. Janowska, Hannah E.R. Baughman, Christopher N. Woods, et al.

For additional articles in this collection, see http://cshperspectives.cshlp.org/cgi/collection/

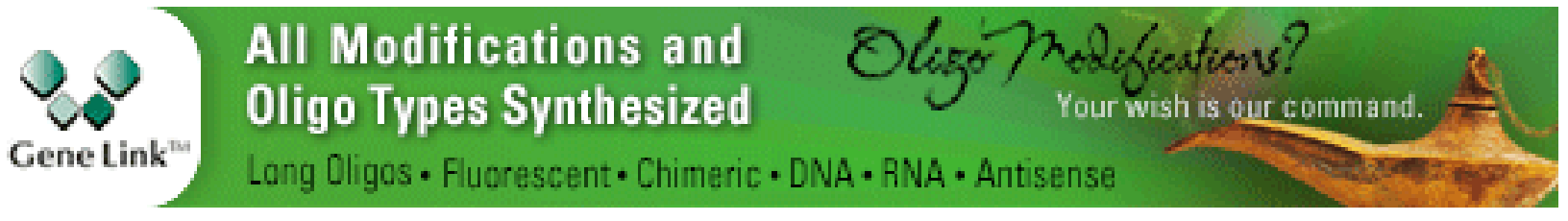


The Nuclear and DNA-Associated Molecular Chaperone Network

Zlata Gvozdenov, Janhavi Kolhe and Brian C. Freeman
Structure, Function, and Regulation of the Hsp90 Machinery

Maximilian M. Biebl and Johannes Buchner

For additional articles in this collection, see http://cshperspectives.cshlp.org/cgi/collection/

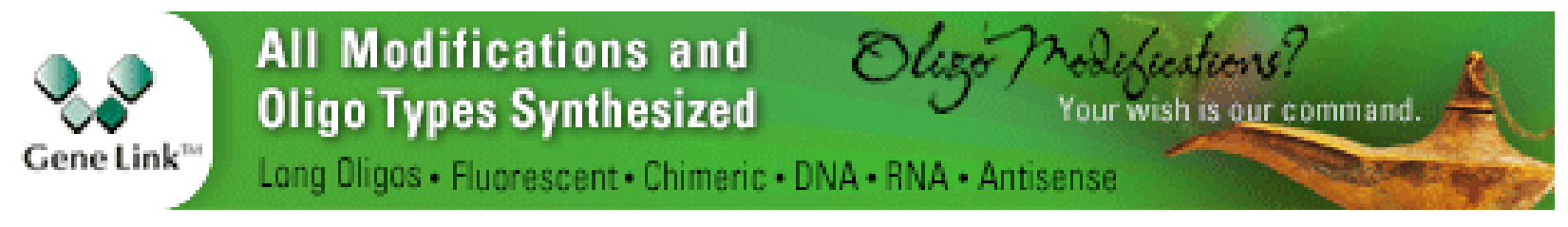

Copyright @ 2011 Cold Spring Harbor Laboratory Press; all rights reserved 